
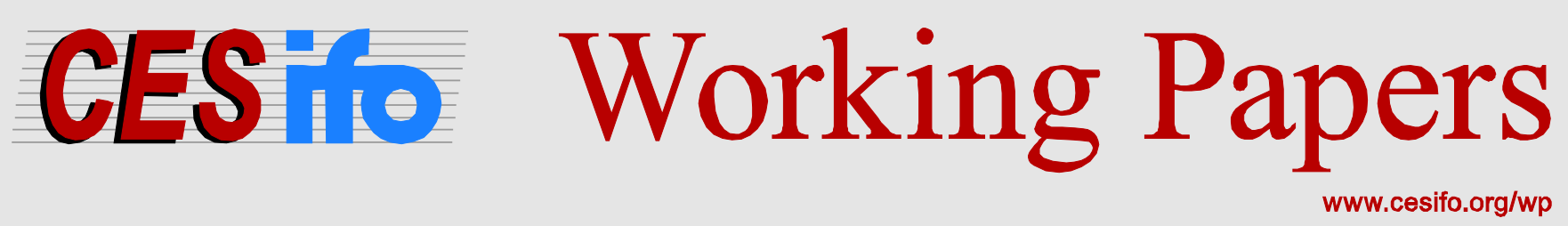

\title{
The Role of Toeholds and Capital Gains Taxes for Corporate Acquisition Strategies
}

\author{
Federica Liberini \\ Antonio Russo \\ Michael Stimmelmayr
}

CESIFO WORKING PAPER NO. 6151

CATEgORY 1: PUBLIC FinANCE

OCTOBER 2016

An electronic version of the paper may be downloaded

- from the SSRN website:

- from the RePEc website:

- from the CESifo website:

WwW.SSRN.com

www.RePEc.org

www.CESifo-group.org/wp 


\title{
The Role of Toeholds and Capital Gains Taxes for Corporate Acquisition Strategies
}

\begin{abstract}
Ownership takeovers often follow complex strategies where the control of the target firm is acquired through a sequence of independent contracts. Based on this observation, we develop a novel theoretical model wherein the acquiring firm decides on the number of steps towards the full ownership of the target (the acquisition structure) and on the combination of cash and stock used to finance the takeover (the method of payment). Within this framework, we analyze the effect of the capital gains tax on these two decision margins and test our theoretical prediction using a bivariate probit model on a sample of acquisition contracts between 2002 and 2014, collected from Bureau van Dijk’s Zephyr database. Our estimates confirm the lock-in-effect and indicate a larger discouraging effect of rising capital gains taxes $(+10 \%$-points increase) on oneshot full acquisition (-6.0\%-points) versus on sequential acquisitions (-5.2\%-points). Further, we provide evidence that an increase in the capital gains tax ( $+10 \%$-points) raises the probability of choosing one-shot full acquisition (+5.5\%-points) instead of sequential acquisitions.
\end{abstract}

JEL-Codes: C250, G340, G320, H250, D220.

Keywords: merger \& acquisition, sequential contract, toehold, capital gains tax, method of payment, lock-in effect.

Federica Liberini

KOF, Department of Management, Technology and Economics

Leonhardstrasse 21

Switzerland - 8092 Zurich

Liberini@kof.ethz.ch
Antonio Russo

KOF, Department of Management, Technology and Economics Leonhardstrasse 21

Switzerland - 8092 Zurich

Russo@kof.ethz.ch

\author{
Michael Stimmelmayr \\ KOF, Department of Management, \\ Technology and Economics \\ Leonhardstrasse 21 \\ Switzerland - 8092 Zurich \\ Stimmelmayr@kof.ethz.ch
}

First Version: March 2014, this Version: October 2016

We thank seminar and conference participants in Zurich, Seattle (APET 2014), Lugano (IIPF 2014), Munich (PSE 2014), Chicago (MFA Annual Conference 2015), Muenster (VfS 2015), Mannheim (ZWE Public Finance Conference 2015) and Berlin (Berlin-Vallendar Conference on Tax Research 2016) for their valuable comments. In particular, we are particularly grateful for the comments by Peter Egger on the empirical part. The usual disclaimer applies. 


\section{Introduction}

Over the last decades, merger and acquisition (M\&A) contracts have become increasingly sophisticated. A striking observation from historical firm-level data is that only about half of all acquisitions listed between 2002 and 2014 correspond to instantaneous, one-shot, full ownership transfers (see Figure 1). For the remaining cases, we largely observe complex acquisition structures, where the acquirer begins with purchasing an initial minority share of the target, a so-called "toehold"1, and then proceeds to gradually increase its participation in the target. Complete ownership is eventually achieved through a sequence of independent transactions.

Based on the prominence of sequential contracts in the market for corporate control, we develop a novel theoretical model, where the acquiring firm decides on the number of steps towards full ownership of the target (the acquisition structure) and on the combination of cash and stock used to finance the takeover (the method of payment). Within this framework, we analyze the role of the capital gains tax on these two decision margins and test our theoretical prediction with the help of a bivariate probit model on a sample of acquisition contracts collected from Bureau van Dijk's Zephyr database.

In the theoretical model, we consider risk averse acquiring shareholders who have alternative means of insuring against the possibility of an unprofitable merger. Referring to the literature on risk containment strategies of sequential acquisitions (see Povel and Sertsios, 2014 and Canil and Rosser, 2004) $)^{2}$, we emphasize the role of the toehold as a screening device which allows the holder to pre-assess whether a merger would create sufficient value to justify additional engagement in the target. Anecdotal evidence for the information-conveying role of the toehold is, for instance, provided by the Américan Móvil and KPN case. ${ }^{3}$ Alterna-

\footnotetext{
${ }^{1}$ Throughout the paper, we refer to the toehold not in the strict sense of a minority acquisition of below $5 \%$ which avoids the trigger of mandatory disclosure requirements. We rather assume that the toehold could be as large as 20\% (see Betton and Eckbo, 2000 and Betton et al., 2009), ensuring its capacity to convey relevant information on the profitability of a potential merger. Further, we do not explicitly model an auction between rival bidders and thus we do not account for the role of the toehold in the bidding process (see Grossman and Hart, 1980; Shleifer and Vishny, 1986; Hirshleifer and Titman, 1990; Burkart, 1995; Singh, 1998; and Bulow et al., 1999). Nevertheless, we account for the fact that the existence of the toehold might have an effect on the takeover premium which we refer to later on as the strategic effect of the toehold.

${ }^{2}$ These papers argue that the prediction of potential synergies from a merger due to economies of scale and scope when combining operations or distribution networks, market power, or the elimination of overlaps, is far from trivial. Therefore, bidders purchase shares of the target to collect information on the potential synergies. This information is crucial for the acquirer's decision whether to stipulate a second contract and to acquire full control over the target.

${ }^{3}$ In May 2012, Américan Móvil, a Mexican telecommunications corporation, purchased 28\% of the Dutch telecommunications company KPN N.V. and stayed, thus, just below the $30 \%$ threshold that would require mandatory takeover. Américan Móvil officially announced its interests were limited to acquiring a minority share, despite the new presence on KPN's board. In August 2013, Américan Móvil unexpectedly withdrew a previous take-over offer. Later, information was released that Américan Móvil had approached the KPN board with proposals of corporate restructuring which had been refused by KPN, unless the offer price for
} 
tively, acquiring shareholders can rely on stock payment to let target shareholders participate in the risk of a low post-acquisition performance of the merged firm. However, both risk containment strategies, the toehold and the stock payment, are costly. On the one hand, the purchase of a (significantly sized) toehold incentivizes the acquirer to bid more aggressively and thus to eventually overpay (see Burkart, 1995; Singh, 1998; or Bulow et al., 1999). ${ }^{4}$ On the other hand, risk sharing with target shareholders via stock payment dilutes the acquirer's voting rights and may thus weaken or even threaten the acquirer's corporate control. ${ }^{5}$ The importance of the corporate control motives for the payment method choice are empirically well validated (see Faccio and Masulis, 2005), and were also of central importance in the failed takeover of Volkswagen (VW) by Porsche. ${ }^{6}$

As previously stated, the model provides the missing theoretical framework that incorporates all of the behavioral margins deemed empirically relevant for the choice of the payment method in corporate takeovers (see Betton et al., 2008). ${ }^{7}$ Therefore, the model enables the analysis of the interplay between different margins, including the tax effect, uncertainty, and corporate control issues, which have so far only been analyzed separately in the empirical literature. In addition to its novelty, the paper is, to our knowledge, the first attempt to explicitly formalize sequential M\&A transactions and analyze the effect of capital gains taxation on the acquisition structure pursued. The theoretical insights highlight that the distinction between the two different types of acquisition strategies plays a key role in isolating the effect of the capital gains tax on the choice of the payment method. In fact, in the sequential acquisition the use of stock payment is solely motivated by the tax-saving incentives, whereas, in the one-shot full ownership transaction the stock payment additionally

the takeover was raised substantially. Clearly, Américan Móvil had the stance that the takeover would be unprofitable at the initial offer price, unless a full reorganization of KPN would have taken place.

${ }^{4}$ According to these papers, the incentive of the toehold bidder to overbid originates in the attempt to induce the rival bidder to bid even higher which enables the toeholder to realize a capital gain on the toehold investment in case the rival bidder wins the contest and purchases the toehold. Empirical evidence in Betton et al. (2009) shows that the return on the toehold may approach the takeover premium itself, even if the toehold is ultimately sold to a rival bidder.

${ }^{5}$ Other prospective tax costs associated with stock payment are referred to as the capitalization effect. See, e.g., Guenther and Willenborg (1999), Lang and Shackelford (2000), or Huizinga et al. (2012).

${ }^{6}$ Starting from September 2005, Porsche, a German sports car manufacturer, continuously increased its participation in the 15-times larger German car manufacturer Volkswagen. By the end of 2008, Porsche was controlling roughly $75 \%$ of the Volkswagen stocks, but at a debt of more than Euro 11 bn, more than $140 \%$ of Porsche's yearly sales. With the onset of the financial crisis, Porsche was not able to prolong its credit lines and had to abandon the takeover. A completion of the merger via stock payments was not an option, as the remaining $25 \%$ share of Volkswagen was worth almost 4 times the value of Porsche and would have reverted the corporate control rights. The failed takeover attempt ended with Porsche being integrated in the Volkswagen conglomerate.

${ }^{7}$ In addition to the direct tax consideration, Betton et al. (2008) discuss the role of information asymmetries and corporate control motives for the choice of the payment method. Even though, we consider uncertainty about the profitability of a merger instead of information asymmetries, both approaches can be considered equivalent in economic terms. The unveiling of information results in ex-post adjustments of stock prices which serve as a compensation mechanism between acquirer and target shareholders. 
serves as an insurance device, as it forces target shareholders to bear some of the uncertainty about the profitability of the merger. This double incentive inherent in the stock payment in the one-shot full acquisition introduces a bias when estimating the effect of the capital gains tax on the payment method. This insight has so far not been accounted for in the empirical literature (see Feldstein et al., 1980; Huang and Walking, 1987; Landsman and Shackelford, 1995; Klein, 1999, 2001, and 2004; Poterba and Weisbenner, 2001; Ayers et al., 2003; Jin, 2006; or Dai et al., 2008, for instance).

Against this background, we depart, in the econometric analysis, from the well-known result that the capital gains tax generates a lock-in effect. That is, the capital gains tax creates a disincentive to use cash (cash-to-stock transaction) vis-a-vis stock (stock-to-stock transaction), as target shareholders demand compensation for the tax penalty associated with the realization of capital gains upon the disposal of their stock in case of the cash payment. In line with the lock-in effect, our estimates confirm that the taxation of capital gains discourages the use of cash in both sequential and one-shot full acquisition contracts. Further, we provide novel evidence that the discouraging effect of the capital gains tax is larger in the one-shot full acquisition vis-a-vis its sequential counterpart. An increase in the capital gains tax by $10 \%$-points reduces the probability of using cash by $1.8 \%$-points in a one-shot full acquisition and by 1.6\%-points in case of a sequential acquisition. This difference becomes by far more significant for targets that are majority-owned by individuals (persons or families). In the latter case, a 10\%-points increase in the capital gains tax reduces the probability of cash financing by $6 \%$-points in the one-shot full ownership transfer, but by only $5.2 \%$-points in the sequential acquisition. These estimates mirror the theoretical insights that the lock-in-effect of the capital gains tax is clouded by the incentive to use stock as an insurance device in the case of a one-shot full ownership transaction. The paper provides a second insight on the significance of the lock-in effect: our estimate provides evidence that the lock-in effect is weak or non-existent if the ownership of the target is spread across multiple owners, but triples in magnitude when the ownership of the target is concentrated among individual shareholders (persons or families). This insight adds to the finding by Ayers et al. (2003) and highlights that not only individuals as shareholders per se matter, but the concentration of individual shareholders. Specifically, a single individual controlling a majority share in the target is most likely endowed with substantial bargaining power and may thus be able to negotiate compensation for the capital gains tax burden associated with a cash payment.

Finally, the paper ventures into uncharted waters by identifying the impact of the capital gains tax on the structure of acquisition contracts. In a situation where cash is, independent of the contract structure, the optimal method of payment and the toehold results in a significant boost of the purchase premium, an increase in the capital gains tax discourages 
the acquirer from choosing a sequential acquisition. The rationale for this finding is based on the fact that the extra capital gains tax burden due to the hike of the takeover premium is so large that it outweighs the initial benefits of the toehold, namely, the low-acquisition price for and the tax savings on the toehold investment.

Our respective model estimate predicts that sequential acquisitions are more frequently financed by cash than by stock and that the probability of choosing a stock-financed, oneshot full acquisition increases by 1.5\%-points following a 10\%-point increase in the capital gains tax in the target's country. In case of a target controlled by an individual (person or family) holding the majority share, the probability of opting for a stock-financed, one-shot full acquisition increases by more than 5.5\%-points after a $10 \%$-point increase in the capital gains tax.

The paper proceeds as follows: Section 2 presents the theoretical model while Section 3 illustrates the empirical analysis. The latter covers our empirical methodology, a description of the data used and a discussion of the regression results. Section 4 concludes.

\section{Theoretical Model}

Firm $A$, the "acquirer", is interested in purchasing firm $B$, the "target", for industrial purposes, e.g., to enter a new market, to increase its production capacity or to exploit economies of scale. The stand-alone value of the acquirer (target) is denoted by $V_{A}\left(V_{B}\right)$. Once completed, the acquisition creates a stochastic value, i.e., a synergy, denoted $\theta$ which is a priori unknown to both firms and distributed as follows:

$$
\theta= \begin{cases}\theta^{H} & p, \\ \theta^{L} & 1-p\end{cases}
$$

with $p \in(0,1)$ and $\theta^{H}>0>\theta^{L}$. The realization of $\theta$ depends on the compatibility between the acquirer and the target. A negative $\theta$ may be due to a lack of interoperability of firms, a poor integration of the target into the acquirer's conglomerate, or simply due to a negative industry shock. These factors cannot be anticipated with certainty at the time of the acquisition; however, there is no asymmetric information between $A$ and $B .{ }^{8}$ The distribution of $\theta$ is common knowledge.

The value of the merged firm is $V_{M}(\theta)=V_{A}+V_{B}+\theta$. In the event that $\theta^{H}\left(\theta^{L}\right)$ is realized, the merger generates profits (losses) and $V_{M}(\theta)$ is larger (smaller) than the sum of

\footnotetext{
${ }^{8}$ Most likely, acquisitions involve a search and matching process. We ignore this fact for simplicity, as our focus is on the part of the acquisition process that comes after matching, that is, the definition of the contractual features of the merger. We assume all acquirer-target pairings to generate strictly positive ex-ante expected pay-off for the acquirer, as implied by the formal condition below.
} 
the values of the two stand-alone firms. The uncertainty about the profitability of the merger impacts the utility of both the acquirer and the target shareholders, as their preferences are represented by a two-moment, mean-variance utility function, $g\left[E\left(\pi_{j}\right), \sigma^{2}\left(\pi_{j}\right)\right]$, with $j \in\{A, B\}$ (see Tobin, 1958; Markowitz, 1970). ${ }^{9}$ That is, the shareholders' utility increases in the expected pay-off, $E\left(\pi_{j}\right)$, but decreases with the variance of the latter, $\sigma^{2}\left(\pi_{j}\right)$.

$$
g\left[E\left(\pi_{j}\right), \sigma^{2}\left(\pi_{j}\right)\right]=E\left(\pi_{j}\right)-\frac{1}{2} \gamma_{j} \sigma^{2}\left(\pi_{j}\right), \quad \text { with } \quad j \in\{A, B\} .
$$

The variable $\gamma_{j} \geq 0$ captures the strength of the shareholders' risk aversion. The expected pay-off arising from the synergies realized through the merger is $E(\theta)=p \theta^{H}+(1-p) \theta^{L}$ and the variance of the synergies is $\sigma^{2}(\theta)=p(1-p)\left(\theta^{H}-\theta^{L}\right)^{2}$.

\subsection{Structure of the Acquisition Contract \& Method of Payment}

The acquisition contract stipulates either a sequential or a one-shot takeover of the target. The sequential acquisition is a two-stage process. In the first stage, the acquirer purchases a minority share $\delta$, the toehold, of the target at a price $\delta V_{B}$. The size $\delta$ of the toehold is exogenous. ${ }^{10}$ In the second stage, the acquirer decides whether to purchase the remaining $(1-\delta)$ fraction of the target, or whether to abandon the merger. By definition, the one-shot acquisition consists of a single transaction through which the target is fully acquired.

The benefit associated with a sequential acquisition is the informational content of the toehold. The acquirer receives a perfectly informative signal on the value of $\theta$ at an interim stage, which allows the acquirer to abandon the merger in case $\theta^{L}$ is observed and hence to avoid an unproductive sunk investment. Disclosing uncertainty about the profitability of the merger has, in addition, a positive impact on the acquiring shareholders' utility since the variance of the expected income is eliminated through the toehold.

One potential drawback arising from the sequential acquisition is related to the strategic effect of the toehold. The purchase of a (significant) toehold by the acquirer most likely impacts the behavior of rival bidders and thus affects the target's valuation in the continuation game. We denote the change in the value of the target due to the toehold investment by $V_{B}^{T}$ and refer to the difference, $\left(V_{B}-V_{B}^{T}\right)$, as the strategic effect of the toehold. In principle,

\footnotetext{
${ }^{9}$ The mean-variance approach resembles a perfect substitute for and coincides with the expected utility (EU) framework approach, if the location-scale condition is met. The latter requires that all random variables in the choice set are linearly related to one another (see, e.g., Sinn, 1990; Eichner and Wagener, 2004).

${ }^{10}$ The opportunity to acquire a toehold may, for example, come in the form of providing "growth capital" to the target firm. In this case, the target decides on the amount of shares made available to the toeholder (see, e.g., Povel and Sertsios, 2014). Another justification for assuming a fixed size for the toehold refers to the fact that many countries set legal limits on the amount of shares that can be controlled by a different company without the requirement of launching a full acquisition bid. This practice constitutes a legal cap on the size of the toehold.
} 
this effect can be either positive or negative. Empirical evidence suggest that, independent of whether the toehold bidder wins the contest, the return on the toehold investment may be as large as the takeover premium itself (see Betton et al. 2009). Accordingly, one expects $\left(V_{B}-V_{B}^{T}\right)<0$ to hold. A theoretical rationale explaining this outcome is found in the auction models by Burkart (1995), Singh (1998), or Bulow et al. (1999). The fact that the acquirer has purchased a significant toehold in the target incentivizes the acquirer to bid more aggressively and induce rival bidders to also increase their bids. The larger the rival bids, the larger is the capital gain the acquirer can realize on the toehold investment in case a rival bidder wins the contest and purchases the toehold. ${ }^{11}$ The initial stand-alone values of both firms $V_{A}$ and $V_{B}$ are independent of the acquisition structure pursued.

In the event of a positive signal, $\theta^{H}$, the acquirer makes a take-it-or-leave-it offer to the target shareholders. This offer, $(x, s)$, specifies an amount of cash, $x \geq 0$, in exchange for the target's stocks (a cash-to-stock payment) and an equity payment, $s$, with $\bar{s}>s \geq 0$, in the form of a stock-to-stock transfer. ${ }^{12,13}$ As it becomes clear below, the method of payment has substantial corporate control, risk bearing, and tax implications for both the acquiring and the target shareholders.

Keeping in mind that the toehold discloses the uncertainty about the gains of the merger and that the merger is completed only with probability $p$, the acquiring and the target shareholders' utilities coincide with their respective expected pay-offs, $g_{j}^{T}=E\left(\pi_{j}^{T}\right), j \in$ $\{A, B\},{ }^{14}$

(a) $g_{A}^{T}=p\left[\left(1-s^{T}\right) V_{M}\left(\theta^{H}\right)-x^{T}-\delta V_{B}-s^{T} \phi V_{M}\left(\theta^{H}\right)\right]+(1-p)\left[V_{A}-\delta\left(V_{B}-V_{B}^{T}\right)\right]$,

(b) $g_{B}^{T}=p\left[s^{T} V_{M}\left(\theta^{H}\right)+(1-\tau) x^{T}+\delta V_{B}\right]+(1-p)\left[V_{B}^{T}+\delta\left(V_{B}-V_{B}^{T}\right)\right]$.

Superscript $T$ indicates the event of the sequential acquisition. The pay-off to acquiring shareholders, (3a), consists of the share $\left(1-s^{T}\right)$ in the merged firm, $V_{M}\left(\theta^{H}\right)$, minus the cash payment to target shareholders, $x^{T}$, and the acquisition price of the toehold, $\delta V_{B}$. The use of equity finance additionally incurs costs associated with the loss of corporate control of

\footnotetext{
${ }^{11}$ Aggressive bidding behavior of the toeholder may, however, also deter rival bidders (see Betton et al., 2009). This is in line with previous empirical evidence by Betton and Eckbo (2000) who find that larger toeholds, which might even exceed $50 \%$ of the target's stocks, are associated with lower offer premiums. However, against the background of a substantial bid jump from the initial to the second bid, representing a premium increase of $31 \%$ on average (Betton and Eckbo, 2000), even a negative correlation between the toehold size and the offer premium may still imply $\left(V_{B}-V_{B}^{T}\right) \leq 0$ to hold, particularly if the toehold is not too large.

${ }^{12}$ The natural threshold $\bar{s}=0.5-\epsilon$ denotes the maximum share of equity finance which ensures that the acquiring shareholders remain the controlling shareholders in the merged firm.

${ }^{13}$ In case the acquirer is short of cash or liquid assets, cash finance will generally require debt financing. For simplicity, we suppress debt finance and subsume it under cash financing.

${ }^{14}$ Due to the informational content of the toehold, uncertainty about the profitability of the merger is eliminated and thus, pay-offs are of zero variance in the sequential acquisition.
} 
size $s^{T} \phi V_{M}\left(\theta^{H}\right)$. The latter reflect monetary and organizational costs originating from the dilution of the acquiring shareholders' voting power and the threat of weakening or losing corporate control through a stock-to-stock transaction. ${ }^{15}$ Thus, corporate control concerns are likely to provide incentives for using cash over equity finance in an acquisition. In case the merger is abandoned, acquiring shareholders are left with firm value $V_{A}$ and an eventual gain on the toehold, namely if $\delta\left(V_{B}-V_{B}^{T}\right)<0$.

The pay-out to target shareholders, $(3 \mathrm{~b})$, includes an ownership share in the merged firm, $s^{T} V_{M}\left(\theta^{H}\right)$, the net of tax cash payment, $(1-\tau) x^{T}$, with $\tau$ denoting the capital gains tax, and the sales proceeds from the toehold, $\delta V_{B}$. The cash payment made by the acquirer entails additional tax costs of $\tau x^{T}$, since the target shareholders demand compensation for the tax burden faced when liquidating their shares, thus realizing all capital gains accrued prior to the merger. Hence, under cash finance, the taxation of realized capital gains generates an increase of the sale price which is referred to as the lock-in effect of capital gains taxation (see, among others, Feldstein et al., 1980; Landsman and Shackelford, 1995; Reese, 1998; Poterba and Weisbenner, 2001; Klein, 2001 and 2004; Ayers et al., 2003; Jin, 2006; Dai et al., 2008). Consistent with this literature, we assume that the target shareholders accept a cash-to-stock transaction only if they are compensated for the incurred capital gains tax burden by the acquirer. As a consequence, cash finance becomes increasingly expensive the higher the capital gains tax. Contrary to that, in the case of equity pay, (i.e. a stock-tostock transaction), stocks are not sold but exchanged. Target shareholders receive a fraction $s$ of the merged firm in return for their stocks and the taxation of accrued capital gains can be deferred indefinitely. In the event the merger is abandoned, the pay-out to target shareholders consists of firm value $V_{B}^{T}$ and a potential loss on the sales proceeds from the toehold, namely if $\delta\left(V_{B}-V_{B}^{T}\right)<0$.

If the acquisition is structured as a one-shot event, the uncertainty about the profitability of the merger vanishes only once the takeover is completed. Accounting for the variance of the expected pay-offs, the utilities of the acquiring and target shareholders are given by

$$
\begin{aligned}
& \text { (a) } g_{A}=(1-s) E\left[V_{M}(\theta)\right]-x-s \phi E\left[V_{M}(\theta)\right]-\frac{1}{2} \gamma_{A}(1-s)^{2} \sigma^{2}(\theta)-\kappa \\
& \text { (b) } g_{B}=s E\left[V_{M}(\theta)\right]+(1-\tau) x-\frac{1}{2} \gamma_{B} s^{2} \sigma^{2}(\theta)+\kappa, \quad \text { with } \kappa=\frac{1}{2} \gamma_{B} s^{2} \sigma^{2}(\theta)
\end{aligned}
$$

From the point of view of the risk-averse acquirer, in the one-shot acquisition, equity finance carries the additional advantage of sharing the uncertainty about the profitability of the

\footnotetext{
${ }^{15}$ Faccio and Masulis (2005) show that the loss of control is strongest, and acquiring shareholders are most vulnerable, if they exert only an intermediate level of voting power ranging from 20 to 60 percent and if the ownership of the target is concentrated. Contrary to that, if acquiring shareholders hold a super-majority of voting rights and the target ownership is rather diffuse, equity pay (a stock-to-stock transaction) is unlikely to threaten the continuation of corporate control. See also Anihud et al. (1990) or Harris and Raviv (1988), and Stulz (1988), for a discussion on ownership positions and the risk of losing control through stock issuance.
} 
merger with the target shareholders (that is, risk sharing reduces the volatility of the acquiring shareholders' pay-off). Through the stock-to-stock transaction, target shareholders become minority owners in the merged firm and are no longer able to side-step the risk of an unprofitable merger. Target shareholders, however, require compensation for the increased volatility of their income. For simplicity, we assume that the respective compensation payment, $\kappa$, always takes the form of a side payment. Risk sharing is beneficial for the acquiring shareholders as long as the decline in utility under risk sharing is less than bearing the uncertainty about the profitability of the merger by oneself. The formal condition states $\gamma_{B} \leq\left(\frac{2}{s}-1\right) \gamma_{A} \cdot{ }^{16}$

Figure 2: Structure of the Game

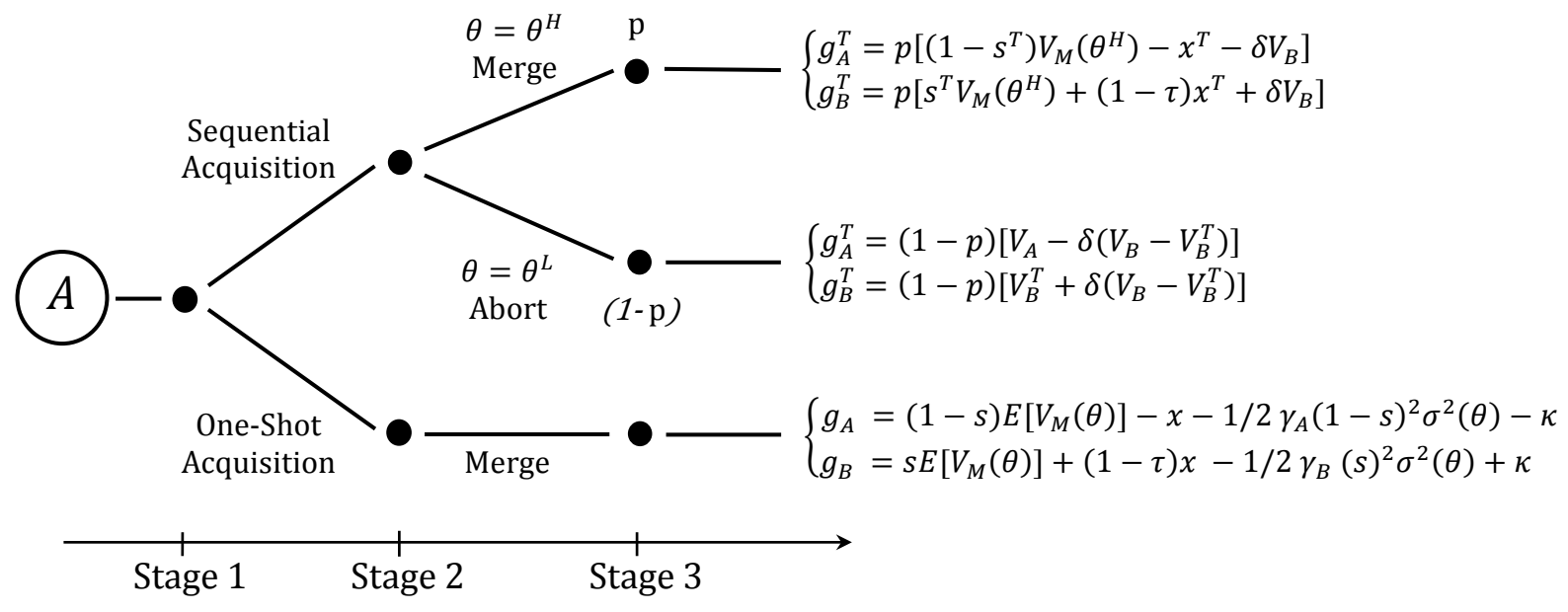

The timing of events is summarized in Figure 2. At Stage 1, $A$ decides whether to acquire a toehold in $B$ or to opt for the one-shot acquisition. If the toehold is acquired, both $A$ and $B$ receive a perfectly informative signal on the value of $\theta$. At Stage $2, A$ decides whether to proceed with the merger and, if so, a take-it-or-leave-it offer to the target shareholders is made. At Stage 3, $\theta$ is realized and all parties receive their state-dependent pay-offs. We solve the model by backward induction.

\subsection{Optimal Financing Behavior \& Decision to Merge}

If $\theta=\theta^{H}$ is observed in the sequential acquisition, the acquirer formulates a contract which ensures that the merger is completed at Stage 2. That is, the contract has to satisfy the

\footnotetext{
${ }^{16}$ At the natural threshold $\bar{s}=0.5-\epsilon$, risk sharing is profitable even if the target shareholders degree of risk aversion is three times larger than the one of the acquiring shareholders, i.e., $\gamma_{B} \leq 3 \gamma_{A}$.
} 
participation constraint of the target shareholders which states

$$
\begin{aligned}
s^{T} V_{M}\left(\theta^{H}\right)+(1-\tau) x^{T}+\delta V_{B} & \geqq V_{B}^{T}+\delta\left(V_{B}-V_{B}^{T}\right) \\
\Rightarrow x^{T} & \geqq \max \left[0 ; \frac{(1-\delta) V_{B}^{T}-s^{T} V_{M}\left(\theta^{H}\right)}{1-\tau}\right] .
\end{aligned}
$$

Combining (5) and (3a), the acquirer's problem reduces to the following first order condition

$$
\frac{\partial g_{A}^{T}}{\partial s}=\frac{\partial E\left(\pi_{A}^{T}\right)}{\partial s}: \quad p\left[-V_{M}\left(\theta^{H}\right)+\frac{V_{M}\left(\theta^{H}\right)}{1-\tau}-\phi V_{M}\left(\theta^{H}\right)\right] \lesseqgtr 0 .
$$

Each dollar financed by equity (stock-to-stock transaction) bears the marginal cost of not participating in the merger gains and a marginal loss of control (first and third term in the squared bracket in (6)), but also grants a marginal benefit in the form of tax savings (second term in the squared bracket in (6)). As long as the costs associated with the loss of corporate control are relatively high compared to the tax costs, it is optimal for the acquirer to offer no stock and rely entirely on cash financing. Instead, if the loss of control costs are sufficiently low, pure stock financing is the optimal method of payment.

$$
\begin{array}{lllll}
\text { (a) } \quad x^{T}=\frac{(1-\delta) V_{B}^{T}}{(1-\tau)} & \text { and } & s^{T}=0 & \text { if } & \tau<\frac{\phi}{1+\phi} \\
\text { (b) } \quad x^{T}=0 & \text { and } & s^{T}=\frac{(1-\delta) V_{B}^{T}}{V_{M}\left(\theta^{H}\right)} & \text { if } & \tau \geq \frac{\phi}{1+\phi}
\end{array}
$$

In the sequential acquisition, the completion of the merger depends entirely on the realization of $\theta$. Specifically, the merger is abandoned if $\theta=\theta^{L}$. Even for $\theta=\theta^{H}$, the acquirer has the option of abandoning the merger. For simplicity, we assume that the gains of the merger are sufficiently large and, hence, completing the takeover is always profitable upon observing $\theta^{H} \cdot{ }^{17}$

Contrary to the above analysis, in the case of the one-shot acquisition, the uncertainty about the gains created by the merger dissolves only at Stage 3 after the merger has been consummated. Using the definitions of $V_{M}(\theta)$ and $\sigma^{2}(\theta)$ provided above, target shareholders

\footnotetext{
${ }^{17}$ The respective formal condition states $\theta^{H}>\left[\frac{1}{1-\tau}-1\right](1-\delta) V_{B}^{T}$ if $s^{T}=0$ and $\theta^{H}>s \phi V_{M}(\theta)$ if $x^{T}=0$. The synergies emerging from the merger need to be large enough to cover at least the capital gains tax costs in case of cash finance, or the loss of control costs in case of equity finance.
} 
accept the acquirer's offer only if ${ }^{18}$

$$
\begin{aligned}
s E\left[V_{M}(\theta)\right]+(1-\tau) x & \geqq V_{B}, \\
\Rightarrow x & \geqq \max \left[0 ; \frac{V_{B}-s E\left[V_{M}(\theta)\right]}{1-\tau}\right] .
\end{aligned}
$$

Similar to (5), the capital gains tax generates a lock-in effect in the case of cash finance. The size of the lock-in effect varies, however, with the underlying acquisition structure. In the sequential acquisition, the lock-in effect occurs only with probability $p$ and falls only on the remaining $(1-\delta)$ fraction of the target firm. Depending on the direction and the size of the strategic effect, the latter additionally enhances (or diminishes) the lock-in effect, depending on $V_{B}<(>) V_{B}^{T}$. Anticipating that (8) is binding in equilibrium and accounting for (4a), the acquirer's optimal share of equity finance $s$ in the one-shot acquisition follows from

$$
\frac{\partial g_{A}}{\partial s}:-E\left[V_{M}(\theta)\right]+\frac{E\left[V_{M}(\theta)\right]}{1-\tau}-\phi E\left[V_{M}(\theta)\right]+\left[(1-s) \gamma_{A}-s \gamma_{B}\right] \sigma^{2}(\theta) \lesseqgtr 0
$$

The interpretation of the first three terms in (9) is identical to those in (6). The additional last term captures the risk insurance effect associated with equity finance in the one-shot acquisition. Letting target shareholders participate in the uncertain proceeds of the merger serves as a beneficial insurance device, reducing the volatility of the acquiring shareholders' pay-off relative to a situation where acquiring shareholders bear the full uncertainty about the profitability of the merger. ${ }^{19}$ Thus, the insurance effect provides, in addition to the tax incentive, an additional rationale for the use of equity finance. Even if the capital gains tax is zero, the insurance effect may be sufficient to ensure that equity is the optimal method of payment in the case of the one-shot acquisition.

The optimal financing of the one-shot acquisition follows from

$$
\begin{array}{lllll}
\text { (a) } x=\frac{V_{B}}{1-\tau} & \text { and } & s=0 & \text { if } & \tau<\frac{\tilde{\phi}(s)}{1+\tilde{\phi}(s)} \\
\text { (b) } x=0 & \text { and } & s=\frac{V_{B}}{E\left[V_{M}(\theta)\right]} & \text { if } & \tau \geq \frac{\tilde{\phi}(s)}{1+\tilde{\phi}(s)}
\end{array}
$$

with $\tilde{\phi}(s) \equiv \phi-\left[(1-s) \gamma_{A}-s \gamma_{B}\right] \frac{\sigma^{2}(\theta)}{E\left[V_{M}(\theta)\right]}$. The cash-financed one-shot acquisition is optimal if both the tax saving and the benefit of risk sharing are low relative to the loss of corporate control associated with equity finance. If, however, the loss of control costs are of only minor concern while the tax savings or the benefit associated with risk sharing are substantial in

\footnotetext{
${ }^{18}$ Without loss of generality, we assume in (8) that the payment to compensate target shareholders the volatility in their expected pay-off in case of the stock-financed one-shot acquisition is always made in form of a side payment which is not affected by the capital gains tax.

${ }^{19}$ See footnote 16 for the formal requirement which renders risk-sharing beneficial for acquiring shareholders.
} 
relative terms, stock becomes the optimal mode of finance in the one-shot acquisition.

To summarize, equity finance carries the benefit of saving on the tax costs associated with the realization of capital gains under cash finance. At the same time, equity finance may weaken or even threaten corporate control. In the one-shot acquisition, equity finance has the additional feature of providing a partial insurance against an unprofitable merger by shifting part of the uncertain proceeds from the acquiring to the target shareholders. This insurance incentive prevails even if capital gains are untaxed. If the uncertainty about the profitability of the merger is, however, revealed through the toehold, the insurance motive of equity finance vanishes and cash becomes the optimal source of finance if capital gains are untaxed.

Proposition I: All else equal, cash finance is more likely in case of the sequential vis-a-vis the one-shot acquisition, as the toehold eliminates the downside risk of the merger. Hence, equity finance becomes superfluous as a means of risk sharing in the sequential acquisition.

Proposition II: Irrespective of the contract structure, an increase in the capital gains tax discourages the use of cash finance. This effect is stronger in the one-shot vis-a-vis the sequential acquisition, where the effect is additionally magnified due to the insurance motive inherent to equity finance.

\subsection{Equilibrium Choice of the Acquisition Structure}

At Stage 1, the acquirer decides on the structure of the acquisition contract anticipating the optimal method of finance. Figure 3 shows the relative importance of the tax costs, $\tau$, vis-a-vis the loss of control costs $\phi$ or the loss of control costs net of the insurance effect, $\tilde{\phi}(s)$, for the optimal method of finance. ${ }^{20}$ In light of the results of the previous section, three different scenarios are considered.

\section{Low Capital Gains Tax}

If the capital gains tax is relatively low compared to the loss of control costs net of the insurance effect, that is, $\tau<\frac{\tilde{\phi}(s)}{1+\tilde{\phi}(s)}$, cash finance is the optimal method of payment irrespective of the acquisition structure. The acquirer opts for the sequential acquisition if the gains (costs) arising from this type of acquisition are larger (lower) than the one emerging from

\footnotetext{
${ }^{20}$ In the case of the one-shot acquisition, the loss of control costs are adjusted by the positive effect arising from the insurance effect, the benefit arising from sharing the uncertainty about the profitability of the merger with target shareholders.
} 
Figure 3: Optimal Method of Finance

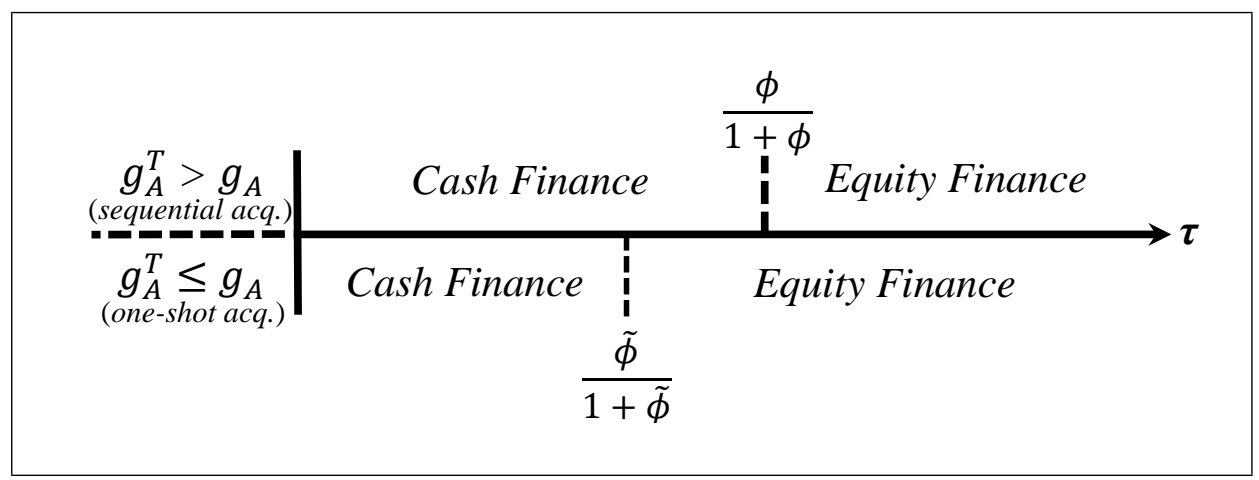

the one-shot acquisition, $\left.g_{A}^{T}\right|_{s^{T}=0} \geq\left. g_{A}\right|_{s^{F}=0}$, or

$$
-\delta\left(V_{B}-V_{B}^{T}\right)-p\left[\frac{1}{1-\tau}-1\right](1-\delta) V_{B}^{T} \geq(1-p) \theta^{L}-\left[\frac{1}{1-\tau}-1\right] V_{B}-\frac{1}{2} \gamma_{A} \sigma^{2}(\theta)
$$

The costs of the cash-financed sequential acquisition comprise the tax costs associated with the purchase of the remaining $(1-\delta)$ fraction of the target firm at the increased price $V_{B}^{T}$ (second term on the left hand side of (11)) net of the potential gain on the toehold investment as $\delta\left(V_{B}-V_{B}^{T}\right)<0$ if $V_{B}<V_{B}^{T}$. In the sequential acquisition, the tax costs materialize, however, only with probability $p$, namely if the merger is actually consummated. The costs of the cash-financed one-shot acquisition (right hand side of (11)) include the expected loss from an unprofitable merger, $(1-p) \theta^{L}$, the tax costs associated with the purchase of the (whole) target firm, and, additionally, the costs originating from risk bearing, i.e. the volatility in income (last term in (11)). To ease interpretation, (11) is re-arranged to highlight under which condition the sequential acquisition is beneficial,

$$
-(1-p) \theta^{L}+\frac{1}{2} \gamma_{A} \sigma^{2}(\theta)+\left[\frac{1}{1-\tau}-1\right]\left[V_{B}-p(1-\delta) V_{B}^{T}\right] \geq \delta\left(V_{B}-V_{B}^{T}\right) .
$$

The advantage of the sequential acquisition rests on the informational content of the toehold (first two terms in $\left(11^{\prime}\right)$ ) and the reduced tax costs (third term in $\left(11^{\prime}\right)$ ). Specifically, the informational benefit comprises the expected gain from, first, avoiding an unprofitable merger if $\theta=\theta^{L}$ realizes and, second, from unveiling the realization of $\theta$ at an interim stage and hence removing the downside risk of the merger which eliminates the volatility of income. The tax benefit of the sequential vis-a-vis the one-shot acquisition originates from the fact that the lock-in effect only burdens the remaining $(1-\delta)$ fraction of the target firm and occurs only with probability $p$, namely if the merger is actually completed. If the increase in the target firm's value under the sequential acquisition is however substantial, i.e. $V_{B}^{T}>\frac{V_{B}}{p(1-\delta)}$, the tax effect can also turn into a disadvantage. The right hand side of (11') denotes the 
costs of the sequential acquisition and captures the potential loss in the value of the toehold which depends on the direction and the strength of the strategic effect.

To summarize, under cash financing, the effect of a marginal increase in the capital gains tax on the acquisition structure is undetermined - the structure depends on the direction and the strength of the strategic effect. If the strategic effect is strong and raises the target shareholders' outside option, the strategic effect also inflates the compensation payment required by the target shareholders and thereby the magnitude of the lock-in effect. In this case, a marginal increase in the capital gains tax raises the relative profitability of the one-shot vis-a-vis the sequential acquisition.

\section{Intermediate Capital Gains Tax}

If the capital gains tax is of intermediate size, that is, $\frac{\phi}{1+\phi} \geq \tau \geq \frac{\tilde{\phi}(s)}{1+\tilde{\phi}(s)}^{21}$, cash is still the optimal method of finance in the sequential acquisition, whereas the use of equity is optimal in the one-shot acquisition. The condition indicating when the sequential acquisition should be undertaken states $\left.g_{A}^{T}\right|_{s^{T}=0} \geq\left. g_{A}\right|_{x=0}$ and implies

$$
-\delta\left(V_{B}-V_{B}^{T}\right)-p\left[\frac{1}{1-\tau}-1\right](1-\delta) V_{B}^{T} \geq(1-p) \theta^{L}-s \phi E\left[V_{M}(\theta)\right]-\frac{1}{2}\left[\gamma_{A}(1-s)^{2}-\gamma_{B} s^{2}\right] \sigma^{2}(\theta)
$$

The interpretation of the left hand side of (12) is identical to the one in (11). The costs emerging in case of a equity financed one-shot acquisition include the expected loss from an unprofitable merger, $(1-p) \theta^{L}$, the costs associated with the loss of control under equity finance, $s \phi E\left[V_{M}(\theta)\right]$, and the costs originating from risk bearing, i.e., the volatility of income, $\frac{1}{2}\left[\gamma_{A}(1-s)^{2}-\gamma_{B} s^{2}\right] \sigma^{2}(\theta)$.

Obviously, a marginal increase of the capital gains tax strengthens the lock-in effect and with it the tax costs of the sequential acquisition, while the costs of the equity financed oneshot acquisition remain unaltered by the marginal tax change. Hence, a marginal increase of the capital gains tax reduces the likelihood of the sequential acquisition being chosen.

\section{High Capital Gains Tax}

Finally, in the case where the capital gains tax is high relative to the loss of control costs, that is, $\tau \geq \frac{\phi}{1+\phi}$, equity is the optimal source of finance irrespectively of the acquisition structure. The decision to choose a sequential vis-a-vis a one-shot contract depends on $\left.g_{A}^{T}\right|_{x^{T}=0} \geq\left. g_{A}\right|_{x=0}$, and implies

$$
-\delta\left(V_{B}-V_{B}^{T}\right)-p s^{T} \phi V_{M}\left(\theta^{H}\right) \geq(1-p) \theta^{L}-s \phi E\left[V_{M}(\theta)\right]-\frac{1}{2}\left[\gamma_{A}(1-s)^{2}-\gamma_{B} s^{2}\right] \sigma^{2}(\theta) .
$$

\footnotetext{
${ }^{21}$ The inequality is fulfilled for $s<\gamma_{A} /\left(\gamma_{A}+\gamma_{B}\right)$. In the case of identical risk aversion between the acquirer and the target shareholders, the condition simplifies to $s<0.5$. Further, the measure of dispersion, $\frac{\sigma^{2}(\theta)}{E\left[V_{M}(\theta)\right]}$, is positive given that the preassigned minimum value for $E\left[V_{M}(\theta)\right]$.
} 
The sequential acquisition is beneficial if the costs associated with the loss of control costs, $s^{T} \phi V_{M}\left(\theta^{H}\right)$, emerging with probability $p$, net of the gain on the toehold investment, $-\delta\left(V_{B}-\right.$ $V_{B}^{T}$ ) (namely if $V_{B}<V_{B}^{T}$ ), are smaller than the costs of the equity financed one-shot acquisition, already discussed in (12). Evidently, under equity finance, the choice of acquisition structure is insulated from the capital gains tax. Besides that, the sequential acquisition is more likely to appear, if the degree of uncertainty about the value created by the merger is large ( $p$ is relatively small) and if there is a significant downside risk involved with the acquisition ( $\theta^{L}$ is relatively large and negative). The latter effect is additionally magnified by the acquirer's aversion to risk (large $\left.\gamma_{A}\right)$.

Proposition III: Independent of the contract structure, if cash is the optimal method of finance and the strategic effect substantially strengthens (weakens) the target shareholders' outside option, a marginal increase in the capital gains tax reduces (increases) the likelihood of the sequential contract been chosen. The same holds for an intermediate level of the capital gains tax, when it is optimal to finance the sequential acquisition by cash and the one-shot acquisition by equity.

Proposition IV: If equity is the preferred method of payment in both the sequential and the one-shot acquisition, a marginal increase in the capital gains tax has no effect on the choice of the contract structure.

\section{Empirical Analysis}

\subsection{Econometric Approach}

The theoretical framework shows that, when acquisitions are motivated by the realization of economic synergies, the method of payment and the contract structure are chosen strategically. In this context, cash finance guarantees full control of the newly merged firm but generates tax costs due to the realization of capital gains upon the handover of the target shares. Equity finance, on the other hand, allows sharing the risk of an unprofitable merger with the target shareholders but weakens the acquirer's control of the newly merged firm. Concerning the contract structure, the sequential acquisition, i.e. the toehold, serves as a mechanism to unveil the potential of the merger but it may also incentivize the toehold bidder to bid more aggressively and eventually overbid which might result in a potential increase in the target acquisition price.

The theoretical model brings four propositions which highlight the effect of capital gains taxation on the method of finance and the contract structure. The aim of the empirical analysis is to test the validity of these propositions. 
To this end, we adopt a two-equation model in the fashion of a seemingly unrelated regression, where the two discrete choices are correlated and jointly determined. Our unit of observation is contract $i_{\mathrm{AB}}$ (for simplicity denoted as $i$ ) between acquirer $A$ and target $B$, completed in year $t$ and leading to the majority control of $A$ over $B$. We do not observe the acquirer's expected pay-off from a sequential acquisition $\left(g\left(\pi_{\mathrm{A}}^{\mathrm{T}}\right)\right)$, or the exact volume of cash used for the transaction $(x)$, but we are able to collect information on whether the acquirer already controlled a share of the target $\left(D^{\mathrm{T}}=1\right)$ prior to the execution of the contract and whether a cash payment was made to finance the transaction $\left(D^{\mathrm{C}}=1\right)$. Each contract is observed once, but contracts are completed in different years. Therefore, we adopt the notation proposed by Moffit (1993) in the context of pseudo-panels, and index the $i^{t h}$ contract completed at time $t$ as $i_{(t)}$. This indicates that the $i^{\text {th }}$ contract is not the same from one period to the next, and that the number of observations, $N(t)$, varies across periods. We specify the following bivariate probit model

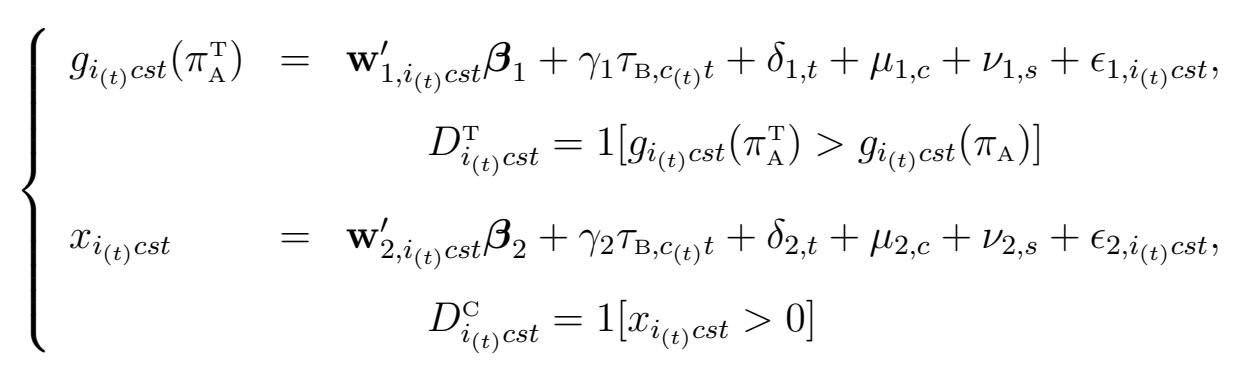

where $c$ denotes the country where the target $\mathrm{B}$ is located, s denotes the industrial sector in which it operates, $\mathbf{w}_{i c s}=\left(\mathbf{w}_{1, i c s}, \mathbf{w}_{2, i c s}\right)$ are vectors of exogenous variables, $\tau_{\mathrm{B}, c}$ is the capital gains tax rate of the country the target firm is located in, $\delta_{t}, \mu_{c}$ and $\nu_{s}$ are, respectively, timeinvariant, target-country specific and sector-specific fixed effects. The error term is assumed to follow a bivariate normal distribution $\left(\epsilon_{1, i c s}, \epsilon_{2, i c s} \mid \mathbf{w}_{i c s}, \tau_{\mathrm{B}}\right) \sim N_{2}(0, \boldsymbol{\Omega})$, where $\boldsymbol{\Omega}$ has offdiagonal element $\rho=\operatorname{Corr}\left(\epsilon_{1, i c s}, \epsilon_{2, i c s}\right)$, such that the joint probability entering the likelihood

function is $\operatorname{Prob}\left(D_{i_{(t)} c s t}^{\mathrm{T}}=d_{i_{(t)} c s t}^{\mathrm{T}}, D_{i_{(t)} c s t}^{\mathrm{C}}=d_{i_{(t)} c s t}^{\mathrm{C}} \mid \mathbf{w}_{i_{(t)} c s t}, \tau_{\mathrm{B}, c_{(t)} t}\right)=\Phi_{2}\left[\mathbf{w}_{i c s}^{\prime} \boldsymbol{\beta}, \gamma_{1} \tau_{\mathrm{B}}, \gamma_{2} \tau_{\mathrm{B}}, \rho\right]$. Under the hypothesis that $\rho$ equals zero, the model would reduce to two independent probit equations. One advantage associated with the bivariate probit specification is that it allows us to estimate the joint conditional mean functions for the probability of our outcome variables and compute the partial effects of interest.

\section{Hypothesis I}

Following Proposition I, we expect our estimates to predict that cash finance is more likely chosen in the sequential vis-a-vis the one-shot acquisition,

$$
\widehat{\operatorname{Pr}}\left[D_{i_{(t)} c s t}^{\mathrm{C}}=1 \mid\left(D_{i_{(t)} c s t}^{\mathrm{T}}=1\right), \mathbf{w}_{i_{(t)} c s t}, \tau_{\mathrm{B}, c(t)}\right]>\widehat{\operatorname{Pr}}\left[D_{i_{(t)} c s t}^{\mathrm{C}}=1 \mid\left(D_{i_{(t)} c s t}^{\mathrm{T}}=0\right), \mathbf{w}_{i_{(t)} c s t}, \tau_{\mathrm{B}, c(t)} t\right] .
$$


The explanation for Proposition I is based on the insight that the toehold discloses the uncertainty about the profitability of the merger, and, hence, equity finance is no longer needed to insure against an unprofitable merger. This is, however, not true for the one-shot acquisition, where the uncertainty about the gains of the merger unveils only after the full takeover is completed.

\section{Hypothesis II}

With regard to the method of finance, we are interested in estimating the size of the lock-in effect, i.e., to which extent the likelihood of using a cash-to-stock transaction decreases as the capital gains tax in the target's country increases. The taxation of capital gains generally encourages the use of equity finance to avoid the tax burden associated with realization of capital gains under cash finance. According to Proposition II, we conjecture that this tax effect on the financing decision is stronger (more negative) in case of one-shot vis-a-vis sequential acquisitions,

$\frac{\partial \widehat{\operatorname{Pr}}\left[D_{i_{(t)} c s t}^{\mathrm{C}}=1 \mid D_{i_{(t)} c s t}^{\mathrm{T}}=0, \mathbf{w}_{i_{(t)} c s t}, \tau_{\mathrm{B}, c_{(t)} t}\right]}{\partial \tau_{\mathrm{B}, c_{(t)}} t}<\frac{\partial \widehat{\operatorname{Pr}}\left[D_{i_{(t)} c s t}^{\mathrm{C}}=1 \mid D_{i_{(t)} c s t}^{\mathrm{T}}=1, \mathbf{w}_{i_{(t)} c s t}, \tau_{\mathrm{B}, c_{(t)} t}\right]}{\partial \tau_{\mathrm{B}, c_{(t)} t}}<0$.

The rational for Hypothesis II rests on the finding that the lock-in effect in case of the sequential acquisition, (i), occurs only with probability $p$ (that is, if the merger is actually consummated), and (ii), it falls only on the remaining fraction $(1-\delta)$ of the target. This indicates a smaller lock-in effect in case of the sequential vis-a-vis the one-shot full acquisition. $^{22}$ In addition, the insurance effect inherent to equity finance in case of the one-shot full acquisition provides an extra incentive for the use of equity, which further increases the sensitivity of the financial choice under the one-shot full acquisition.

This mechanism also paves our way to formulate a novel strategy to identify the pure effect of the capital gains tax on the financing method in merger and acquisitions. Only in case of sequential acquisitions can the tax effect on the financial decision be isolated, while in the case of the one-shot full ownership acquisition the identification of the tax effect on the financial decision is overlain by a double incentive, namely the tax saving and the insurance effect.

\section{Hypothesis III}

The effect of the capital gains tax on the choice of the contract structure varies across different scenarios. If the costs associated to the loss of control are high relative to the capital gains

\footnotetext{
${ }^{22}$ If the strategic effect is, however, very strong and negative, the increase in the purchase price of the remaining $(1-\delta)$ fraction of the target could magnify the size of the lock-in effect substantially in case of the sequential acquisition. Thus, depending on the success probability $p$ and the strength of a negative strategic effect, the lock-in effect may in effect be larger in a sequential vis-a-vis a one-shot full acquisition.
} 
tax costs, and if the toehold incentivizes the toehold bidder to bid more aggressively and ultimately to overbid, inflating the purchase price of the target, an increase of the capital gains tax rate reduces the likelihood of choosing a sequential acquisition (see Proposition III). The result leaves us with the testable hypothesis that the partial effect of an increase in the capital gains tax on the joint probability of choosing a sequential acquisition financed by cash is negative,

$$
\frac{\partial \widehat{\operatorname{Pr}}\left[D_{i_{(t)} c s t}^{\mathrm{C}}=1, D_{i_{(t)} c s t}^{\mathrm{T}}=1 \mid \mathbf{w}_{i_{(t)} c s t}, \tau_{\mathrm{B}}\right]}{\partial \tau_{\mathrm{B}}}<0
$$

\section{Hypothesis IV}

Alternatively, if the loss of control costs are sufficiently small to induce an unconditional preference for equity finance, the choice of the contract structure is independent of the capital gains tax. To verify the validity of Proposition IV, we test whether the partial effect of the capital gains tax on the joint probability of choosing a sequential acquisition financed by equity is non-significantly different from zero,

$$
\frac{\partial \widehat{\operatorname{Pr}}\left[D_{i_{(t)} c s t}^{\mathrm{C}}=0, D_{i_{(t)} c s t}^{\mathrm{T}}=1 \mid \mathbf{w}_{i_{(t)} c s t}, \tau_{\mathrm{B}}\right]}{\partial \tau_{\mathrm{B}}}=0 .
$$

A practical implication of the bivariate probit model is that we can expand our specification and generalize the model by allowing the choice of the contract structure, $D_{i}^{\mathrm{T}}$, to be endogenous to the second equation (see Greene, 1996 and 2008). ${ }^{23}$ This approach accounts for the fact that, following the theoretical model, the financing method is conditional on having already chosen the acquisition contract structure. The bivariate probit takes the following recursive form:

$$
\left\{\begin{array}{c}
g_{i_{(t)} c s t}\left(\pi_{\mathrm{A}}^{\mathrm{T}}\right)=\mathbf{w}_{1, i_{(t)} c s t}^{\prime} \boldsymbol{\beta}_{1}+\gamma_{1} \tau_{\mathrm{B}, c_{(t)} t}+\delta_{1, t}+\mu_{1, c}+\nu_{1, s}+\epsilon_{1, i i_{(t)} c s t}, \\
D_{i_{(t)} c s t}^{\mathrm{T}}=1\left[g_{i_{(t)} c s t}\left(\pi_{\mathrm{A}}^{\mathrm{T}}\right)>g_{i_{(t)} c s t}\left(\pi_{\mathrm{A}}\right)\right] \\
x_{i_{(t)} c s t}=\lambda D_{i_{(t)} c s t}^{\mathrm{T}}+\mathbf{w}_{2, i_{(t)} c s t}^{\prime} \boldsymbol{\beta}_{2}+\gamma_{2} \tau_{\mathrm{B}, c_{(t)}}+\delta_{2, t}+\mu_{2, c}+\nu_{2, s}+\epsilon_{2, i_{(t)} c s t}, \\
D_{i_{(t)} c s t}^{\mathrm{C}}=1\left[x_{i_{(t)}} c s t>0\right] .
\end{array}\right.
$$

\footnotetext{
${ }^{23}$ The idea behind this identification strategy is the decomposition of the four probability terms entering the likelihood function into the product of the conditional and the marginal distribution of the endogenous variable. In the specifics of our application, the endogeneity of the contract structure with regard to the method of finance decision can be ignored when formulating the log-likelihood, because $\operatorname{Prob}\left(D^{\mathrm{T}}=d^{\mathrm{T}}, D^{\mathrm{C}}=\right.$ $\left.d^{\mathrm{C}}\right)=\operatorname{Prob}\left(D^{\mathrm{C}}=1 \mid D^{\mathrm{T}}=1\right) \operatorname{Prob}\left(D^{\mathrm{T}}=1\right)$.
} 


\subsection{Acquisition Data}

We collect a dataset of acquisition contracts completed and executed between the 1st of January 2002 and the 31st of December 2014. Our source is the commercial database Zephyr, provided by the Bureau van Dijk. For each contract, we observe the identity of the acquirer and the target firm, the size of the stakes involved in the deal, the method of payment, and the characteristics of the shareholders that had control over the target before the acquisition. This sample is merged with information on the financial accounts and on the historical ownership of the acquirer and the target, collected from Orbis, a second database distributed by the Bureau van Dijk. The initial raw sample contains 260,500 completed acquisition contracts. $^{24}$

Zephyr classifies acquisitions as being financed by "cash", "equity shares", "debt" or "other". Among contracts with a known financing method, the large majority (approximately 85\%) is financed by a single type of payment. In all remaining cases, we identify the financing method that accounts for the largest portion of the deal value. We discard observations where the fraction of the deal value covered by each payment type is missing. For a small number of contracts, we have multiple acquirers and multiple targets, with no indication of which firm used what method of payment listed in the data. ${ }^{25}$ These cases are also excluded from the analysis, leaving us with a sample of 104,433 acquisitions. The baseline analysis is restricted to the decision of financing the acquisition by cash rather than equity. Additionally, we conduct robustness checks by including debt financed acquisitions as an alternative to cash finance to control that our results are unaffected by the inclusion of financially constrained acquirers.

To identify the contract structure chosen for a given deal (i.e., sequential vis-a-vis oneshot full acquisitions), we combine information on the type of deal with information on the size of the stakes involved in the respective transaction. In particular, Zephyr provides details on the share in the target controlled by the acquirer before stipulating the contract, the share acquired with the transaction and the share in the target finally owned by the acquirer after executing the contract. This information allows us to classify four types of deals: one-shot full acquisitions, where an acquirer purchases the full control of the target at once; initial acquisitions, where an acquirer purchases a first (minority) share of the target; intermediate acquisitions, where an acquirer with a pre-existing hold in the target increases its holdings;

\footnotetext{
${ }^{24}$ Only $1.97 \%$ of all acquisition contracts listed in the database were completed prior to our sample period.

${ }^{25}$ These cases account for $20 \%$ of the contracts with known acquirer and just above $1 \%$ of the contracts with known targets.
} 
and final acquisitions, where an acquirer with a pre-existing hold in the target purchases all remaining shares and becomes the ultimate owner of the target. Due to missing observations, the identification of the contract structure reduces the sample size further, to approximately 62,300 contracts. Table 1 reports the descriptive statistics on the distribution of the four contract types: on average over the sample period, $38 \%$ of the observed contracts are full acquisitions, $21 \%$ are initial minority acquisitions and $25 \%$ are minority share acquisitions.

Our aim is to distinguish deals that involve an acquirer with prior ownership of the target from deals where the acquirer purchases the full control of the target at once. We construct three indicator variables for the choice of completing a sequential vis-a-vis a full acquisition. The variable $D^{\mathrm{T} 1}$ simply distinguishes between full and final acquisitions and constitutes our strict definition of the toehold. To allow for the possibility that the acquirer's objective is to obtain control of the target, without purchasing its full ownership, we construct a second indicator variable, $D^{\mathrm{T} 2}$, which also considers majority initial acquisitions and intermediate acquisitions. Finally, to have a broader definition of sequential acquisitions, we define a third indicator variable, $D^{\mathrm{T} 3}$, where majority acquisitions are included as toeholds. We exclude all initial minority transactions, which correspond to the toehold purchases as defined in the theoretical section. This is done for two reasons: First, Zephyr rarely allows us to track the full sequence of acquisitions involving a specific acquirer-target pair, which makes it difficult to distinguish initial stages of a sequential deal from simple minority acquisitions. ${ }^{26}$ Second, if a full sequence of contracts is observed, the inclusion of the initial transaction would introduce serial correlation with the final stage of the acquisition process. Table 2 summarizes the definition of the three indicator variables which define the contract structure, $D^{\mathrm{Tj}}$ for $j=1,2,3$. The baseline analysis is conducted on the sample defined by $D^{\text {T3 }}$, which includes a total of 34,066 contracts (31,234 when only cash or equity finance are considered), completed by 19,722 acquirers. The samples defined by the other two indicator variables, $D^{\mathrm{T} 1}$ and $D^{\mathrm{T} 2}$, are used to conduct robustness checks. As discussed in Betton et al. (2009), the share of acquisitions using toeholds is non-negligible and, in our case, amounts to approximately $22 \%$ of the overall sample (15 and $17 \%$ when $D^{\mathrm{T} 1}$ and $D^{\mathrm{T} 2}$ are used). Further, cash finance (cash-to-stock transactions) turns out to be the preferred method of payment in over $70 \%$ of contracts. In line with the theoretical framework (Proposition I), the descriptive statistics displayed in Table 2 also show that cash finance is more extensively used in sequential contracts than in one-shot full acquisitions.

We collect further information such as the location of the target and the acquirer firms, their respective industry codes which, along with other characteristics, allow us to partially

\footnotetext{
${ }^{26}$ To include these initial minority transactions we would have to assume that missing final contracts indicate that the acquisition attempt has failed, due to a lack of compatibility among the firms involved in the deal. In other words, we would have to assume that $\theta^{L}$ was realized for every minority initial transaction that was not followed by an observed final acquisition.
} 
control for the informational role of the toehold in the sequential acquisitions. Table 5 reports the distribution of the contracts of our baseline sample over the 42 different countries where target firms are incorporated. Additionally, statistics on the relative frequency of sequential acquisitions, cash finance, domestic takeovers, and same-industry contracts are included. Table 6 repeats the same statistics for all 54 countries in which at least ten different acquirers are located. ${ }^{27}$ To further explore the hypothesis that structural differences across acquirer and target firms are at the root of the contract structure decision, we collect unconsolidated balance sheet information averaged over the two years preceding the announcement of an acquisition. Table 7 allows us to compare the median of several key balance sheet variables across acquirers and targets involved in the different types of contracts. The numbers show that the targets involved in sequential acquisitions are, in absolute terms, usually substantially larger (in terms of financials) than those purchased in one-shot contracts. Moreover, they are more profitable, own a higher volume of assets, and have larger earnings per share. However, these differences become less sharp if expressed relative to the acquiring firm's characteristics. Additionally, in a sequential acquisition, targets are mostly controlled by more than one shareholder, which, in turn, control numerous lower level subsidiaries.

Finally, we collect data on ownership concentration in the target firm prior to the acquisition. Our conjecture is that the loss of control associated to equity finance is particularly costly in cases where the target's ownership is concentrated among few shareholders (or large block holders). In these instances, the target shareholders might seek to preserve some degree of monitoring power over the newly merged firm managerial decisions. When classifying targets according to their historical ownership structure, we proceed in two steps. First, we identify the "main" target shareholder as the one owning the single largest share among all shareholders listed prior to the takeover. ${ }^{28}$ We complement this information, with information on the "predominant" shareholder type, the largest owner after aggregation by type (i.e., individual, industrial company or financial company). This allows us to measure the level of dispersion among all shareholders and shareholder types. In a second step, we combine information on the main (and predominant) shareholder with the degree of "independence" of the target, as provided by the Bureau van Dijk. In Orbis, a firm is considered independent if it is not directly or indirectly controlled by any other corporation. With this we classify targets as having concentrated ownership if they are not controlled by other corporations and if their main or predominant shareholder is an individual (person or family). In the econometric analysis, we allow the tax effect on the contract structure to vary across the main (or predominant) shareholder type, as well as across the level of target pre-deal ownership concentration.

\footnotetext{
${ }^{27}$ Our sample includes a total of 20,100 acquirers, located in 59 countries. The large majority of the acquirers $(72 \%)$ are involved in only one acquisition.

${ }^{28}$ In case of sequential acquisitions, we exclude the acquirer from the list of shareholders.
} 


\subsection{Capital Gains Tax Data}

The tax disadvantage associated with cash-to-stock transactions in M\&As arises because target shareholders demand compensation for the tax burden on the accrued capital gains. However, this additional premium can become sufficiently high to dissuade the acquirer from making the acquisition. In the context of the theoretical model, the rate relevant for the method of payment and contract structure is the long-term individual capital gains tax rate of the country where the target firm is located. We depart from the World Personal Tax Guides (published yearly by Ernst \& Young) and collect data on the top statutory tax rate that applies to "capital gains accrued from the individual sale of shares, assets, stocks, and bonds that have been held for a long period" (which, in most countries, is equal to five years). As shown in Table 8, countries follow different regimes in the treatment of capital gains. Most European countries treat capital gains derived from the sale of corporate shares as separate income and apply a specific tax rate. A second group of countries treat capital gains as ordinary income and apply the regular personal income tax rate to it. For these countries, we use the top statutory personal income tax rate as the relevant tax measure. Finally, Bermuda, Cayman Islands, Hong Kong, Switzerland, Taiwan, and Turkey treat capital gains as separate, tax exempt income.

The existing literature has put forth the approaches to account for firm characteristics which may affect the sensibility of M\&A transactions to capital gains taxes. Ayers et al. (2003) find evidence of a significant difference in the magnitude of the lock-in effect on takeover premiums for privately versus institutionally owned firms. Day et al. (2008) estimate both the capitalization and the lock-in effect induced by the Taxpayer Relief Act of 1997 and show that trading volumes were larger for stocks with a high percentage of mutual fund ownership. Blouin et al. (2011) use firm-level shareholder composition and exploit the 2003 U.S. reduction in the dividend and capital gains tax to show that individual investors are the only ones affected by changes in shareholder taxes.

To account for the varying exposure to capital gains taxes, we collect information on the legal structure of the target and on the characteristics of the shareholders in control of the target prior the announcement of the acquisition. Regarding the legal form of the target, we consider any Public Authority, Governmental Institution, Mutual \& Pension Fund, Trust, Foundation, and Research Institute as exempted from capital gains taxation. Targets with different legal forms, such as private limited companies, for instance, are classified according to the identity of their controlling shareholder, as defined in the previous section. We expect the lock-in effect to be weaker for non-individual shareholders, as the capital gains tax is levied at the personal level, with industrial and commercial companies mostly exempt from this kind of taxation. We further control for the nationality of the shareholders, identifying cases where the target is controlled by foreign corporations or individuals. This is 
relevant because some countries apply different tax rates for capital gains accrued by foreign shareholders. In one of our robustness checks, we account for these particular rules.

Table 4 reports the average capital gains tax rate conditional on the contract structure, the method of payment, and the type of shareholders controlling the target before the announcement of the acquisition. These unconditional means show that, first, on average over the sample period, sequential acquisitions financed by stock-to-stock transactions face a higher capital gains tax than sequential acquisitions financed by cash-to-stock transactions; and, second, acquisitions financed by cash-to-stock transactions face, on average, a lower capital gains tax in sequential versus one-shot, full acquisitions. This suggests that the sensitivity of capital gains taxes is higher in sequential acquisitions where equity finance does not additionally insure against a bad merger outcome. Moreover, the difference between the average capital gains tax in cash-to-stock sequential versus one-shot, full acquisitions is insignificant in the case of target firms controlled by corporate shareholders. This finding is in line with Blouin et al. (2011) who show that individual shareholders have a higher sensitivity to changes in the capital gains tax.

\subsection{Empirical Results}

The results of the bivariate probit model in equation (14) are presented in Table 9. In the analysis we resort to the dichotomus variable $D^{\mathrm{T} 3}$ to estimate the joint probability of choosing a sequential acquisition and financing the transaction by cash. We observe 31,234 contracts executed by 19,722 acquirers over the twelve years between 2002 and $2014 .^{29}$ The unconditional joint probability between these two variables suggests that cash-financed sequential acquisitions are $6 \%$ less frequent than equity-financed one-shot ones and $14 \%$ more frequent than equity-financed sequential acquisitions. Cash-financed one-shot acquisitions represent the most frequent form of contracts with an unconditional probability of 0.52 . The tetrachoric correlation between the two binary choice variables of interest is estimated as 0.237 with a standard error of 0.010 .

As to the different specifications of Table 9, in column [a] we control only for the statutory long-term individual capital gains tax rate of the target country. In column [b], we also account for alternative capital gains tax regimes (i.e., we distinguish whether capital gains are treated as separate income, ordinary personal income, or whether capital gains are exempted from taxation in the target country). In column [c], the baseline specification is repeated excluding contracts with targets located in countries where capital gains are part of the ordinary personal income. In column [d], the model is augmented with acquirer country- and industry-specific fixed effects. In column [e], the errors are clustered at the acquirer level, and,

\footnotetext{
${ }^{29}$ Our baseline specification excludes contracts where the finance method is listed as "debt" or "other".
} 
finally, in column [f] we add additional controls. All specifications also include target countryand industry-fixed effects, as well as year dummies. As controls, we include indicators for the complexity of the target ownership structure, accounting for the number of subsidiaries directly controlled by the target prior the acquisition (with 0 being the default), a dummy indicating whether the target has concentrated ownership and two dummies controlling for acquirers that were insolvent or unprofitable in the two years preceding the acquisition.

We initially find that sequential and cash-financed acquisitions are more likely in the case of targets located in countries that exempt capital gains from any form of taxation. This result might be driven by the strong presence of tax havens (namely Bermuda, Cayman Islands, Hong Kong, Singapore, Switzerland, Taiwan, and Turkey) in our sample, which tend to exempt capital gains from taxation. Thus, the estimated coefficient captures the effect of profit shifting incentives associated with the purchase of firms located in these countries. However, this result is not robust to the introduction of acquirer country-fixed effects.

The estimates reported in each column of Table 9 suggest that the capital gains tax has a negative impact on the probability of both structuring the acquisition as a sequential contract and financing it by cash as predicted in our theoretical model. However, we find that the significance of the tax coefficient for the contract structure choice fades as we add additional fixed effects and control variables. When we distinguish, in column [b], between different fiscal regimes, we find that treating capital gains as ordinary personal income does not significantly affect the tax coefficient. Nevertheless, we decide to exclude the contracts involving targets under this type of regime (column [c]), because shareholders whose capital gains are aggregated with ordinary personal income might have alternative ways to alter their tax burden, compared to shareholders for whom capital gains are taxed as separate income. Regarding the control variables (column [f]), we find that acquirers purchasing targets located in the same country are more likely to use a sequential contract, but less likely to finance the purchase by cash, whereas acquirers purchasing targets operating in the same industry (specifically, the same 2 digit NACE sector) are less likely to use sequential contracts and cash finance. These results can be explained by the higher uncertainty associated with the acquisition of targets that operate in different (geographical or industrial) markets. In fact, we also find that acquirers favor sequential acquisitions in case the target firm has a complex organizational structure (i.e., numerous subsidiaries), which confirms the argument that the toehold serves an informational role. Also in line with our theoretical model, we find that acquirers prefer sequential contracts and cash finance, if the target features a concentrated (pre-deal) ownership structure. That is, the cash-financed sequential contract is preferred when the loss of corporate control associated with an equity-financed one-shot acquisition is substantial. Finally, the results show that insolvent or unprofitable acquirers are less likely to choose cash finance. This variable also serves as a control for the fact that cash-constrained 
acquirers may be limited in their choice of financing method.

In Table 10 we introduce a series of categorical variables that identify different types of target (pre-deal) shareholders and allow the tax coefficient to vary across contracts according to these different types of target shareholders. Using information on shareholder identity, our sample is reduced to approximately one third of the original size, leaving us with 11,044 contracts completed by 8,307 acquirers. In column [a] we simply repeat the specification of column [f] of Table 9, in column [b] ([c]) we distinguish between target firms whose main (predominant) shareholder prior the acquisition was a company rather than an individual. For the choice of contract structure we now find that the capital gains tax has a negative and significant coefficient for contracts involving target firms whose main (or predominant) shareholder is a person or a family. The overall coefficient, however, drops to zero $(-1.325$ +1.327 ) when target firms are controlled by companies. This findings is in line with the general tax practice of capital gains being subject to taxation at the personal level, exempting companies to avoid multiple taxation.

With regard to the decision of using cash finance, the results surprisingly show that the capital gains tax has no effect on this margin if the pre-acquisition majority owners of the target are individuals. However, when companies are pre-acquisition majority owners of the targets, the capital gains tax has a negative and significant effect on the decision to use cash finance. To reconcile this rather surprising result with the existing empirical literature and our theoretical model, we investigate the heterogeneity of this tax effect further.

First, in [d] and [e] of Table 10, we differentiate between industrial or commercial companies and financial companies as the main or the predominant pre-acquisition target shareholders. The classification of different company types reveals that the tax coefficient is insignificant for targets that are controlled by industrial companies, similar to individuallycontrolled targets. Hence, the significance of the capital gains tax on the decision of using cash finance in the previous specifications (column [b] and $[\mathrm{c}]$ ) is solely driven by target firms controlled by financial companies. One explanation for this outcome is the fact that financial companies, such as hedge funds and financial service companies, represent the interest of individual clients whose investments are managed with the intent of minimizing the clients' tax liability.

Second, the lack of significance of the tax coefficient on the financing decision in case of targets controlled by individuals and families seems to contradict the existing literature as well as our theoretical propositions. One possible explanation for this finding is that targets controlled by individuals are characterized by a high level of ownership dispersion, which results in each individual shareholder not having significant bargaining power on the terms of the acquisition agreement. In column [f], we test this hypothesis by allowing for the tax coefficient to vary according to whether the ownership of the target is dispersed or 
whether a single individual (person or family) is holding a stake larger than $30 \%$ in the target (excluding direct or indirect links to other corporations). In this specification, we find that the tax coefficient in the decision on the sequential acquisition is not significantly different from the tax coefficient when the pre-acquisition ownership of the target is dispersed among several individuals or families. Instead, the coefficient of the tax for the decision of using cash finance is large, negative, and significant for targets controlled by individual shareholders with concentrated ownership. This result is in line with the theoretical framework and the descriptive statistics presented in Table 4. The latter shows that the difference in the average tax rate between cash-financed sequential and one-shot full contracts is larger in the case of targets controlled by individuals (0.116) compared to targets controlled by companies (0.052).

In Table 11 we present diagnostics for both the baseline specification (column [f] in Table 9 ) and for the specification of column [f] in Table 10. We estimate the predicted probabilities and report the percentage of correctly projected positive and negative outcomes and the overall rate of correct classifications for each possible joint and marginal outcome of the contract structure and financing choice. We use 0.5 as the threshold for all joint and marginal outcomes and compute these statistics on the estimation sample of the respective specifications. The two alternative strategies discussed in the theoretical model, the sequential cash-financed contract and the one-shot full equity-financed contract, have an overall prediction rate of $78 \%$ and $82 \%$ ( $85 \%$ and $77 \%$ in the baseline), respectively. Note that the classification is sensitive to the relative size of each component group and always favors classification into the larger group. In fact, we find that, on average among all possible outcomes, over $90 \%$ of the normal weight group is correctly classified (specificity) versus the $25 \%$ of the low weight group (sensitivity).

\section{Partial Tax Effect on the Contract Structure and the Method of Payment}

For the interpretation of the model estimation and to provide a direct test of the four theoretical propositions, we compute the average partial effects of a change in the capital gains tax on the joint and marginal probabilities of interest (equations (13) to (16)), as derived in our preferred empirical specification (column [f] of Table 10). All average partial effects, as displayed in Table 12, are computed on the sample of 11,044 contracts used for the model estimation. Standard errors are obtained using the delta method. The first column reports the overall partial effect common to all different pre-deal target shareholder types. Columns 2-5, instead, display the average partial effects computed for the contracts with specific types of pre-deal target shareholders.

We start from the effect of the capital gains tax on the marginal probabilities, showing that a $10 \%$-point increase in the capital gains tax rate of the target country reduces the 
probability of choosing a sequential contract by $0.2 \%$-point and the probability of using cash finance by $1.8 \%$-points. The magnitude of the effect on the contract structure, a novel result in the literature, is as high as $1.7 \%$-points for targets controlled by individuals. This is of considerable size, given that only $20 \%$ of acquisitions are expected to be completed through sequential contracts. Moreover, the magnitude of the tax effect on the decision of using cash financing becomes larger in target firms controlled by individuals ( $6 \%$ versus $1.8 \%$ points). This evidence, again, shows the higher sensitivity of individual versus corporate shareholders with respect to the capital gains tax.

In line with Proposition I, the model predicts that it is more likely to observe cash financing conditional on having chosen a sequential, instead of a one-shot full acquisition. The predicted probability of the former outcome is 0.766 , while the latter is 0.689 . The effect of a change in the capital gains tax on these two conditional probabilities serves as a test of Proposition II. We find, in line with the theoretical prediction, that a rise in the capital gains tax has a negative and significant effect on both conditional probabilities. The estimate is also slightly larger in the case of a one-shot full acquisition, confirming our conjecture that the insurance effect inherent in equity financing introduces an upward bias on the estimated coefficient. This result provides important evidence for the identification of the lock-in effect, given that cash financing in sequential contracts has purely tax-motivated disincentives.

To test Propositions III and IV, we estimate the joint probabilities of choosing a cashfinanced sequential and an equity-financed sequential contract. As reported in Table 11, the predicted joint probabilities for these two alternative outcomes are such that, on average, cash-financed sequential contracts are three times more likely than their equity-financed counterparts. We also find that a change in the capital gains tax affects the likelihood of the former contract type, but not the latter. In particular, a rise in the capital gains tax by ten percentage points reduces the likelihood of choosing a cash-financed sequential contract by $1.3 \%$-points when targets are controlled by individual shareholders. Moreover, we find that an increase in the capital gains tax does not affect the decision of acquiring a target sequentially using equity finance, whereas the tax does increase the probability of using a one-shot full acquisition financed by equity.

\section{Sensitivity Analysis}

Table 13 presents a set of robustness checks for our preferred specification (column [f] of Table 10). In column [b], we expand the sample and re-include all contracts involving targets located in countries where capital gains are taxed as ordinary personal income. The results presented in column [c] are the outcome of estimating a recursive version of our model, in which we allow the contract structure to directly affect the decision on the finance method. The numbers show that the direct effect is indeed strong and significant. Thus, the recursive version of the model confirms our previous finding that cash is the preferred 
method of finance, conditional on choosing a sequential acquisition. In line with the basic mechanism outlined in the theoretical model, the purchase of the toehold, i.e. opting for a sequential contract, then constitutes an alternative form of "insurance" for those acquirers who do not wish (for whatever reason) to rely on a stock-to-stock transaction to gain control over the target.

In column [d] and [e] we test the sensitivity of our results to the definition of the binary variable for the contract structure, i.e. the definition of the toehold. In the specification of column [d], we exclude all cases of majority share accruals $\left(D^{\mathrm{T} 2}\right)$, where the acquisition process is partitioned in more than two stages. In column [e], we further restrict the baseline sample and refer to a stricter definition of sequential acquisition (i.e., we only include contracts where the complete ownership of the target is achieved $\left.\left(D^{\mathrm{T} 1}\right)\right)$. The estimated coefficients on these two alternative samples are qualitatively similar to those of the baseline estimation. However, as expected, we find that the tax coefficient is larger for the more extensive sample used in our baseline specification.

One possible motive for choosing a sequential acquisition or an acquisition by parts, is that the acquirer may be financially constrained and cannot afford purchasing the whole control of the target at once. To test the sensitivity of our results to the presence of financially constrained acquirers, we estimate a version of the model in which the method of finance is a binary variable taking the value of 1 if cash is chosen and 0 in case of either equity or debt. ${ }^{30}$ This approach allows us to interpret the dependent variable for the financing choice as a dichotomous measure distinguishing between acquirers that are liquid and those that are cash-constrained. The resulting coefficients are reported in column [f] of Table 13. In this case, the tax is found to have an insignificant effect on the finance choice.

\section{Conclusion}

Recent data on completed M\&A transactions of the last decade indicate that sequential acquisitions in particular have become a frequent phenomenon. One rationale for this observation relates to the informational content of the potential gains from a merger conveyed by the initial investment, the so-called toehold. In this study the informational benefit associated with a sequential vis-a-vis a one-shot full ownership transaction serves as our measure to isolate the impact of the capital gains tax on the choice of the payment method, the lock-in effect, in M\&A transactions. In a one-shot full ownership transaction, stock financing serves as a tax saving and an insurance device, while in the sequential acquisition only the tax saving argument justifies the use of stock financing. Thus, neglecting the double incentive

\footnotetext{
${ }^{30} \mathrm{It}$ is worth noting that debt finance is chosen in very few cases, equal to roughly $3 \%$ of all observed contracts.
} 
inherent to stock financing in a one-shot full ownership transaction most arguably results in biased estimates for the lock-in effect. Our results confirm this hypothesis and show a larger estimate of the lock-in effect in the case of a one-shot full ownership transaction vis-a-vis a sequential acquisition. Specifically, a 10\%-points increase in the capital gains tax reduces the probability of cash financing by $6 \%$-points in a one-shot full acquisition, but by only $5.2 \%$-points in a sequential one.

Furthermore, the capital gains tax directly impacts the choice of the acquisition structure. Depending on the sign and magnitude of the strategic effect associated with the toehold, the capital gains tax may either enhance or diminish the probability of choosing a sequential acquisition. Our estimates suggest a negative effect and thus point to an additional downside of the capital gains tax on welfare: if a tax system strengthens incentives to opt for a oneshot full ownership transaction instead of a sequential acquisition, the acquirer is deprived of the flexibility to abort the merger at an interim stage and thus abandon an unprofitable sunk investment.

\section{References}

[1] Anihud, Y. Lev, B. and N.G. Travlos, 1990, "Corporate Control and the Choice of Investment Financing: The Case of Corporate Acquisitions," Journal of Finance, 45, 603-616.

[2] Ayers, B.C., Lefanowicz, C.E., Robinson, J.R., 2003, "Shareholder Taxes in Acquisition Premiums: The Effect of Capital Gains Taxation," Journal of Finance, 58, 2783-2801.

[3] Betton, S., Eckbo, B. E. , 2000, "Toeholds, bid jumps, and expected payoff in takeovers," Review of Financial Studies 13, 841-882.

[4] Betton, S., Eckbo, B.E., Thorburn, K.S., 2008, "Corporate Takeovers" in Handbook of Empirical Corporate Finance, ed. Eckbo, B. E., Elsevier.

[5] Betton, S., Eckbo, B.E., Thorburn, K.S., 2009, "Merger negotiations and the toehold puzzle," Journal of Financial Economics 91, 158-178.

[6] Blouin,J., Raedy, J., Shackelford, D., 2011, "Dividends, Share Repurchases, and Tax Clienteles: Evidence from the 2003 Reductions in Shareholder Taxes", The Accounting Review 86, 887-914.

[7] Bulow, J., Huang, M., Klemperer, P., 1999, "Toeholds and Takeovers," Journal of Political Economy 107, 427-454. 
[8] Burkart, M., 1995, "Initial shareholding and overbidding in the takeover contest", Journal of Finance 50, 1491-1515.

[9] Canil J.M., Rosser, B.A., 2004, "Toehold," The African Finance Journal 6, 37-55.

[10] Carroll, C., Griffith, J.M., 2010, "Toeholds, rejected offers, and bidder gains: Do rebuffed bidders put targets in play to profit from their toeholds?," Quarterly Review of Economics and Finance 50, 214-221.

[11] Dai, Z., Maydew, E., Shackelford, D.A., Zhang, H.H., 2008, "Capital Gains Taxes and Asset Prices: Capitalization or Lock-in?," Journal of Finance 63, 709-742.

payment, and takeover premiums: public and private tender offers in France," Journal of Financial Economics 24, 363-403.

[12] Eichner, T., Wagener, A., 2004, "Relative risk aversion, relative prudence and comparative statics under uncertainty: the case of $(\mu-\sigma)$-preferences," Bulletin of Economic Research 56, 159-170.

[13] Faccio, M., Masulis, R.W., 2005, "The Choice of Payment Method in European Mergers and Acquisitions," Journal of Finance, 60, 1345-1388.

[14] Feldstein M., Slemrod J., Yitzhaki S., 1980, "The effects of taxation on the selling of corporate stock and the realizations of capital gains", Quarterly Journal of Economics, 95, 779-791.

[15] Greene, W. H., 1996, "Marginal Effects in the Bivariate Probit Model" NYU Working Paper No. EC-96-11.

[16] Greene, W. H., Hensher, D. A., 2008, "Modeling Ordered Choices: A Primer and Recent Developments", Cambridge University Press.

[17] Grossman, S.J., Hart, O.D., 1980, "Takeover bids, the free-rider problem, and the theory of the corporation", Bell Journal of Economics 11, 42-64.

[18] Guenther D. A., Willenborg M., 1999, "Capital gains tax rates and the cost of capital for small business: evidence from the IPO market", Journal of Financial Economics, $53,385-408$.

[19] Harris, M., Raviv, A., 1988, "Corporate control contests and capital structure," Journal of Financial Economics, 20, 55-86.

[20] Hirshleifer, D., Titman, S., 1990, "Share Tendering Strategies and the Success of Hostile Takeover Bids," Journal of Political Economy, 98, 295-324. 
[21] Huang, Y.S., Walkling, R.A., 1987, "Abnormal Returns Associated with Acquisition Announcements: Payment Method, Acquisition Form, and Managerial Resistance," Journal of Financial Economics, 19, 329-349.

[22] Huizinga, H., Voget, J., Wagner, W., 2012, "Capital Gains Taxation and the Cost of Capital: Evidence from Unanticipated Cross-Border Transfers of Tax Bases," CEPR Discussion Papers 9151.

[23] Jin, L., 2006. "Capital Gains Tax Overhang and Price Pressure," Journal of Finance 61, 1399-1431.

[24] Klein, P., 1999. "The capital gain lock-in effect and equilibrium returns," Journal of Public Economics 71, 355-378.

[25] Klein, P., 2001, "The capital gain lock-in effect and long-horizon return reversal," Journal of Financial Economics 59, 33-62.

[26] Klein, P., 2004, "The capital gain lock-in effect and perfect substitutes," Journal of Public Economics 88, 2765-2783.

[27] Landsman, W. R. and Shackelford, D. A., 1995, "The Lock-In Effect of Capital Gains Taxes: Evidence from the RJR Nabisco Leveraged Buyout", National Tax Journal, 48(2), 245-259.

[28] Lang, M. H. and Shackelford, D. A., 2000, "Capitalization of capital gains taxes: evidence from stock price reactions to the 1997 rate reduction," Journal of Public Economics, 76(1), 69-85.

[29] Mantecon, T., 2009, "Mitigating risks in cross-border acquisitions," Journal of Banking Ef Finance 33, 640-651.

[30] Markowitz, H., 1970, "The demand for assets under conditions of risk," Journal of Finance 28, 79-96.

[31] Moffitt, R., 1993, "Identification and Estimation of Dynamic Models with a Time Series of Repeated Cross-Sections", Journal of Econometrics, 59, 99-123.

[32] Povel P., Sertsios G., 2014, "Getting to know each other: The role of toeholds in acquisitions", Journal of Corporate Finance, 26, 201-224.

[33] Poterba, J., Weisbenner S., 2001, "Capital gains tax rules, tax-loss trading, and turnof-the-year returns", Journal of Finance, 56, 353-368. 
[34] Reese, W.A., 1998, "Capital gains taxation and stock market activity: Evidence from IPOs", Journal of Finance, 53, 1799-1819.

[35] Shleifer, A., Vishny, R.W., 1986, "Large shareholders and corporate control", Journal of Political Economy 94, 461-488.

[36] Singh, R., 1998, "Takeover Bidding with Toeholds: The Case of the Owner's Curse", Review of Financial Studies 11, 679-704.

[37] Sinn, H.-W., 1990, "Expected utility, $\mu-\sigma$ preferences and linear distribution classes: A further result," Journal of Risk and Uncertainty 3, 277-281.

[38] Stulz, R.M., 1988, "Managerial control of voting rights," Journal of Financial Economics, 20, 25-54.

[39] Tobin, J., 1958, "Liquidity preferences as behaviour towards risk," Review of Economic Studies 25, 68-85. 
Figure 1: Distribution of Full Acquisition Contracts over Time

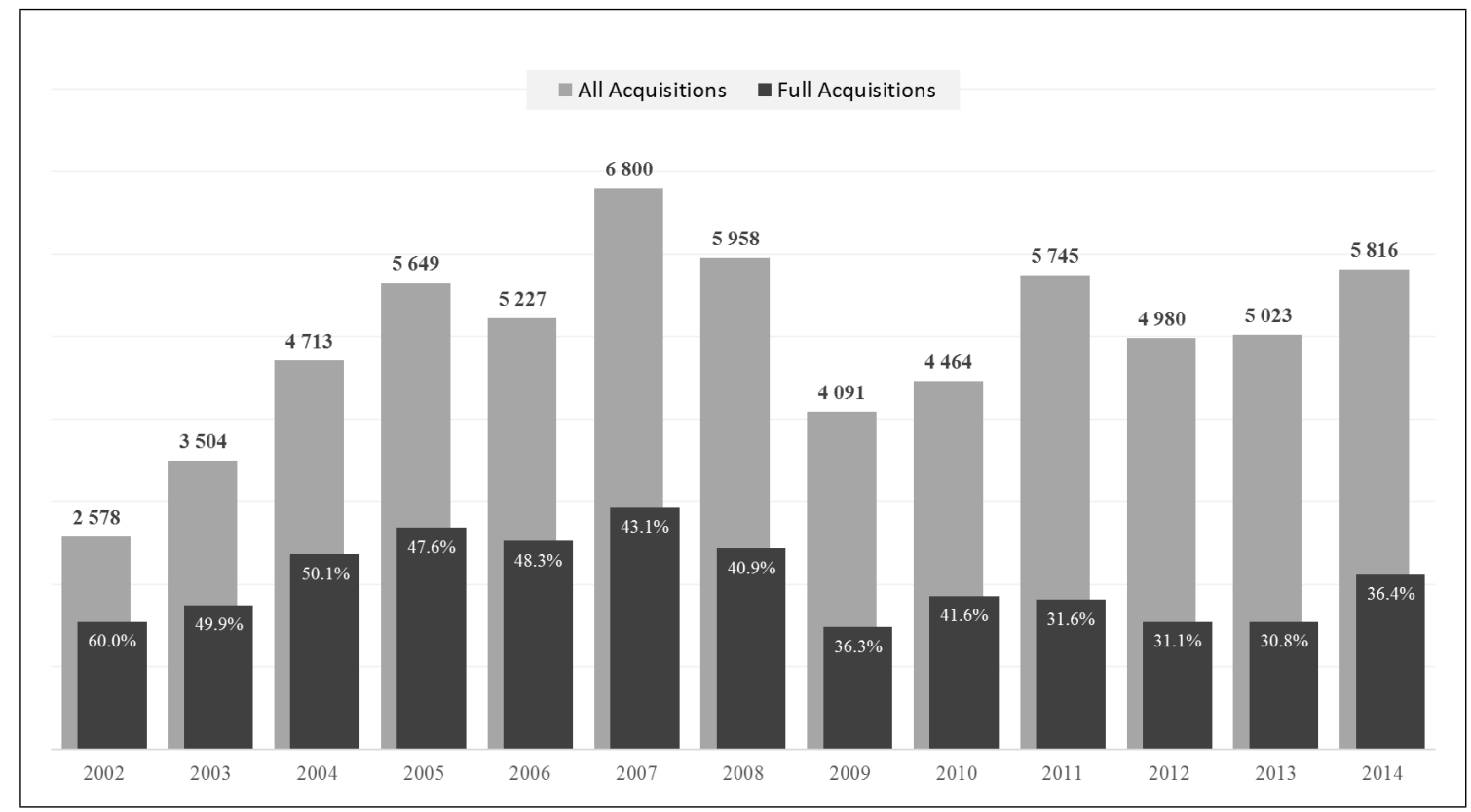

Note: The total sample includes the 64,548 contracts observed over the observational period, while the subset of "full acquisitions" includes all one-shot full acquisitions (0-100) and all initial one-shot majority acquisitions (0-majority), which together account for 23,542 and 3,060 contracts, respectively. 
Table 1: Types of Acquisition Contracts

\begin{tabular}{|c|c|c|c|c|c|}
\hline & \multicolumn{2}{|c|}{ Sample Composition } & \multicolumn{3}{|c|}{ Average Size of Stake Involved } \\
\hline & Frequency & Percentage & Initial \% & Acquired \% & Final \% \\
\hline \multicolumn{6}{|l|}{ Full Deal } \\
\hline 0 to 100 & 23,544 & 37.68 & 0.00 & 100.00 & 100.00 \\
\hline \multicolumn{6}{|l|}{ Initial Deal } \\
\hline 0 to minority & 13,396 & 21.44 & 0.00 & 11.79 & 11.79 \\
\hline 0 to majority & 2,989 & 4.78 & 0.00 & 69.56 & 69.56 \\
\hline \multicolumn{6}{|l|}{ Intermediate Deal } \\
\hline minority to minority & 15,020 & 24.04 & 9.84 & 2.74 & 12.57 \\
\hline minority to majority & 1,028 & 1.65 & 32.34 & 35.41 & 67.74 \\
\hline majority to majority & 2,252 & 3.60 & 68.36 & 11.06 & 79.42 \\
\hline \multicolumn{6}{|l|}{ Final Deal } \\
\hline minority to 100 & 1,175 & 1.88 & 28.04 & 71.94 & 100.00 \\
\hline majority to 100 & 3,078 & 4.93 & 72.09 & 27.91 & 100.00 \\
\hline Total & 62,482 & 100 & & & \\
\hline
\end{tabular}

Note: The table reports the distribution of the types of acquisitions observed in our sample and classified according to the different "phase" of contract completion. The classification is based on information on the share of target ownership controlled by the acquirer before and after completion of the contract.

Table 2: Type of Acquisition Contracts and Method of Payment

\begin{tabular}{lrrrrr}
\hline Type of Acquisition & Cash & Debt & Other & Stock & Total \\
\hline \multirow{2}{*}{ Full Deal } & 14,022 & 1,193 & 1,117 & 7,212 & 23,544 \\
& $59.56 \%$ & $5.07 \%$ & $4.74 \%$ & $30.63 \%$ & \\
Initial Deal & 15,010 & 577 & 85 & 713 & 16,385 \\
& $91.61 \%$ & $3.52 \%$ & $0.52 \%$ & $4.35 \%$ & \\
Intermediate Deal & 17,843 & 140 & 23 & 294 & 18,300 \\
& $97.50 \%$ & $0.77 \%$ & $0.13 \%$ & $1.61 \%$ & \\
Final Deal & 2,857 & 93 & 42 & 1,261 & 4,253 \\
& $67.18 \%$ & $2.19 \%$ & $0.99 \%$ & $29.65 \%$ & \\
& & & & & \\
All Deals & 49,732 & 2,003 & 1,267 & 9,480 & 62,482 \\
& $79.59 \%$ & $3.21 \%$ & $2.03 \%$ & $15.17 \%$ & \\
\hline \hline
\end{tabular}

Note: The table reports details on the distribution of the different modes of finance, conditional on the contract structure. A given contract is classified by the specific method of finance, if this is either the unique one or the predominant one reported in Orbis. We exclude contracts using a mix of finance methods for which we do not observe the relative weight, w.r.t. the final total payment. 
Table 3: Indicator Variables for the Contract Structure

\begin{tabular}{|c|c|c|c|}
\hline & $\begin{array}{c}\text { Number of } \\
\text { Contracts }\end{array}$ & $\begin{array}{c}\text { Percentage } \\
\text { of Cash } \\
\text { Finance }\end{array}$ & Type of Deals Included \\
\hline Basic Toehold Definition & 27,797 & & \\
\hline$D^{\mathrm{T} 1}=1$ & $\begin{array}{c}4,253 \\
(15.30 \%)\end{array}$ & $67.18 \%$ & $\min -100$, maj-100 \\
\hline$D^{\mathrm{T} 1}=0$ & $\begin{array}{c}23,544 \\
(84.70 \%)\end{array}$ & $59.56 \%$ & $0-100$ \\
\hline$D^{\mathrm{T} 1}$ and Majority Control & 31,814 & & \\
\hline$D^{\mathrm{T} 2}=1$ & $\begin{array}{c}5,281 \\
(16.60 \%)\end{array}$ & $70.74 \%$ & min-100, maj-100, min-maj \\
\hline$D^{\mathrm{T} 2}=0$ & $\begin{array}{c}26,533 \\
(83.40 \%)\end{array}$ & $61.57 \%$ & 0-100, 0-maj \\
\hline$D^{\mathrm{T} 2}$ and Multi-stage Acquisitions & 34,066 & & \\
\hline$D^{\mathrm{T} 3}=1$ & $\begin{array}{c}7,533 \\
(22.11 \%)\end{array}$ & $77.29 \%$ & min-100, maj-100, min-maj, maj-maj \\
\hline$D^{\mathrm{T} 3}=0$ & $\begin{array}{c}26,533 \\
(77.89 \%)\end{array}$ & $61.57 \%$ & 0-100, 0-maj \\
\hline
\end{tabular}

Note: The table reports details on the definition of the indicator variables for the sequential vs. the oneshot full acquisition. The classification is based on information on the share of target ownership controlled by the acquirer before and after completion of the contract, as described in Table 1. Initial contracts, formally coinciding with the Toehold acquisitions, are always excluded from the sample. Minority and majority are simply defined with respect to the threshold of $50 \%$.

Table 4: Average Capital Gains Tax Rates for Alternative Contract Structures

\begin{tabular}{|c|c|c|c|c|c|c|}
\hline & \multicolumn{2}{|c|}{ All Acquisitions } & \multicolumn{2}{|c|}{$\begin{array}{l}\text { Acquisition of target with } \\
\text { Individual Shareholders }\end{array}$} & \multicolumn{2}{|c|}{$\begin{array}{c}\text { Acquisition of target with } \\
\text { Corporate Shareholders }\end{array}$} \\
\hline & Full & Sequential & Full & Sequential & Full & Sequential \\
\hline Cash & 0.203 & 0.171 & 0.282 & 0.166 & 0.229 & 0.177 \\
\hline Stock & 0.198 & 0.197 & 0.241 & 0.226 & 0.217 & 0.204 \\
\hline
\end{tabular}

Not: The table reports the average target country's capital gains tax rate, conditional on the contract structure and the method of payment, as measured at the time of contract completion. This is done for the overall sample (column 2 and 3) and then repeated for the subsample of acquisition of targets previously controlled by individuals (or families), and of targets previously controlled by corporations. 


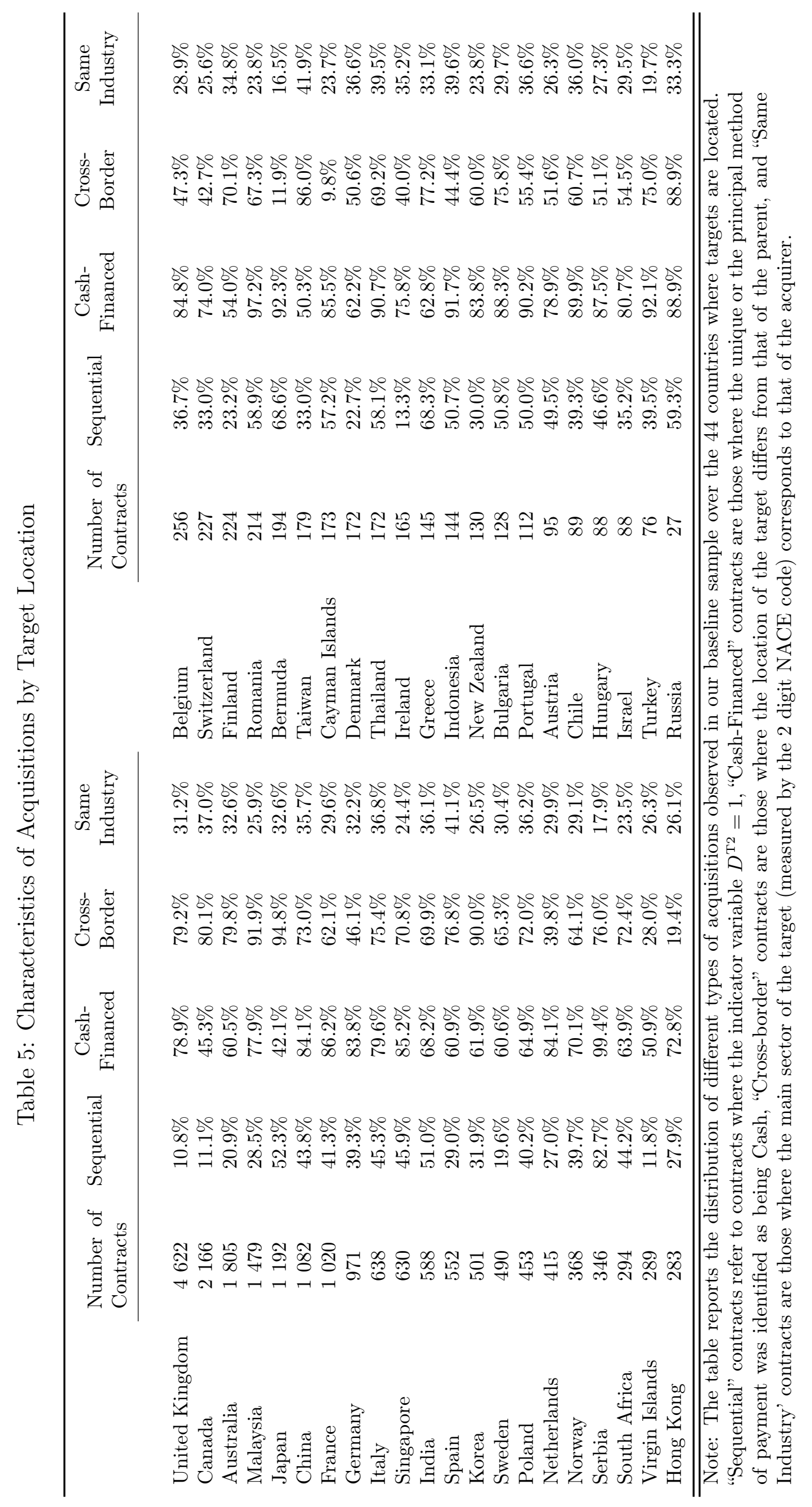




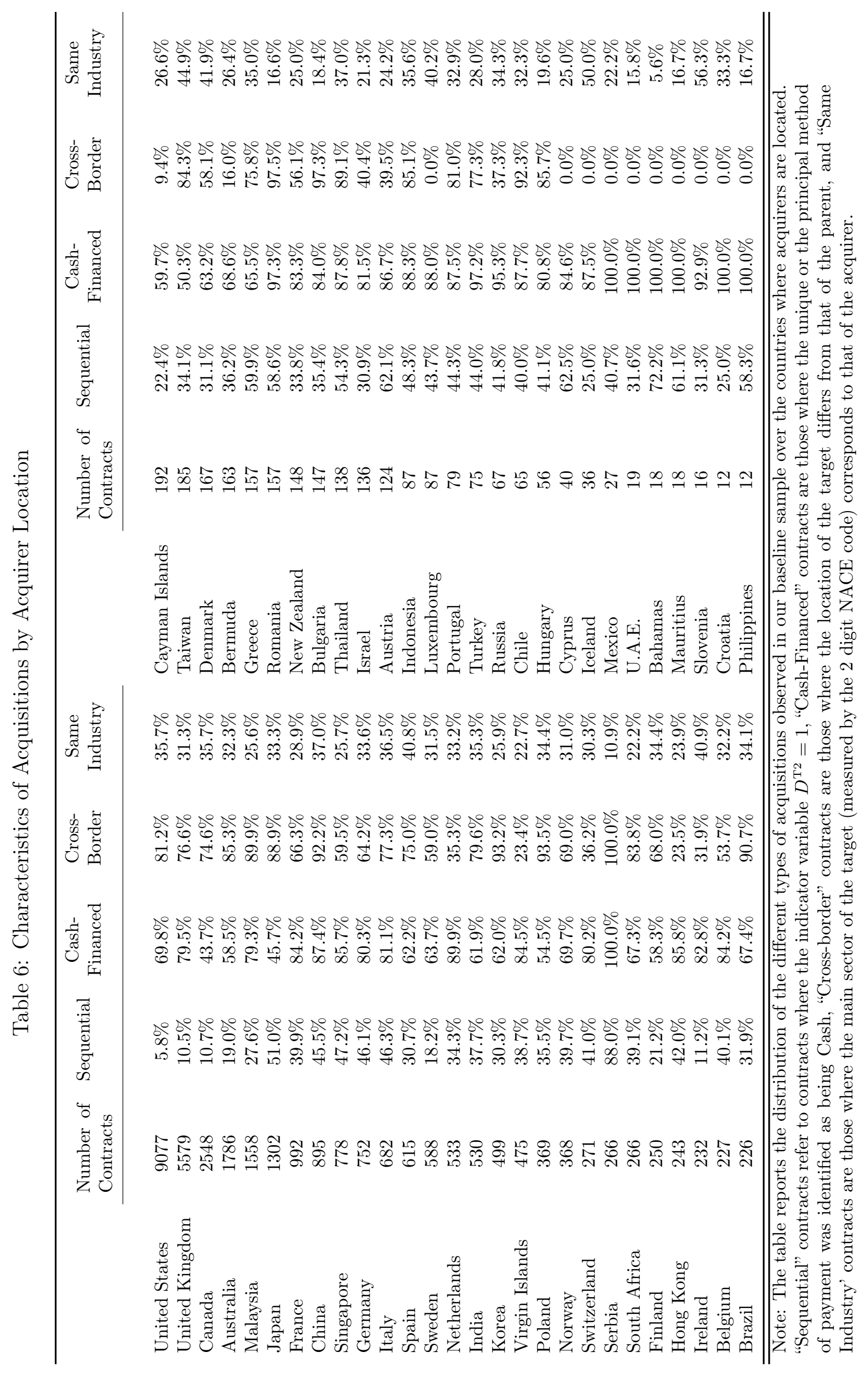




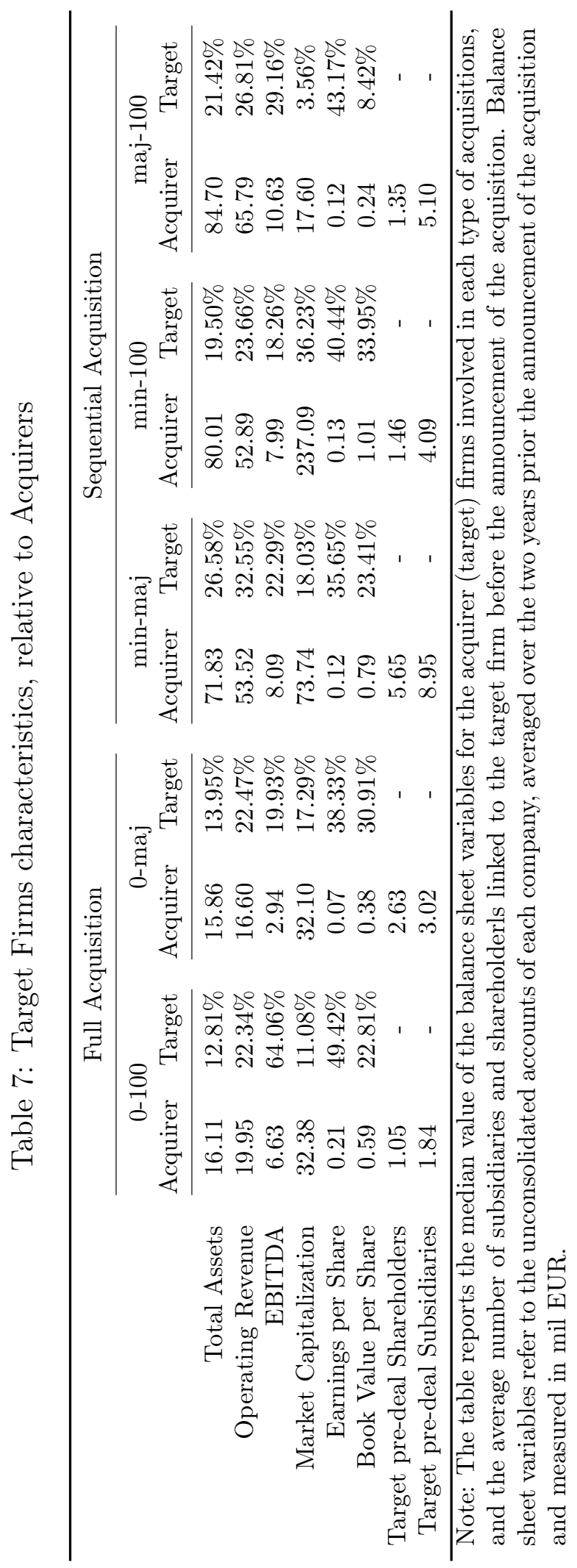


Table 8: Capital Gains Tax Treatment in the Target Country

\begin{tabular}{|c|c|c|c|}
\hline & Average Tax rate & Type of Tax & Note \\
\hline Australia & 0.228 & CGT & \\
\hline Austria & 0.442 & PIT \& CGT & $\begin{array}{l}\text { Capital Gains treated as Separate Income } \\
\text { since } 2012\end{array}$ \\
\hline Belgium & 0.261 & CGT & $\begin{array}{l}\text { Tax only applies on gains from the sale of com- } \\
\text { panies with foreign Shareholders }\end{array}$ \\
\hline Bermuda & 0.000 & CGT & $\begin{array}{l}\text { Gains from the sale of company shares are ex- } \\
\text { empted from taxation }\end{array}$ \\
\hline Brazil & 0.140 & CGT & \\
\hline Bulgaria & 0.100 & CGT & \\
\hline Canada & 0.233 & CGT & \\
\hline Cayman Islands & 0.000 & CGT & $\begin{array}{l}\text { Gains from the sale of company shares are ex- } \\
\text { empted from taxation }\end{array}$ \\
\hline Chile & 0.172 & CGT & \\
\hline China & 0.200 & CGT & \\
\hline Denmark & 0.429 & CGT & \\
\hline Finland & 0.290 & CGT & \\
\hline France & 0.293 & CGT & Regularly Increased the Tax Rate \\
\hline Germany & 0.115 & CGT & \\
\hline Greece & 0.208 & CGT & \\
\hline Hong Kong & 0.000 & CGT & $\begin{array}{l}\text { Gains from the sale of company shares are ex- } \\
\text { empted from taxation }\end{array}$ \\
\hline Hungary & 0.213 & CGT & \\
\hline India & 0.011 & CGT & $\begin{array}{l}\text { Tax only applies on gains from the sale of com- } \\
\text { panies with foreign Shareholders }\end{array}$ \\
\hline Indonesia & 0.331 & PIT & \\
\hline Ireland & 0.239 & CGT & \\
\hline Israel & 0.262 & CGT & \\
\hline Italy & 0.258 & CGT & \\
\hline Japan & 0.205 & CGT & \\
\hline Korea & 0.200 & CGT & \\
\hline Malaysia & 0.023 & CGT & Exempted Capital Gains until 2011. \\
\hline Netherlands & 0.250 & CGT & \\
\hline New Zealand & 0.368 & PIT & \\
\hline Norway & 0.279 & CGT & \\
\hline Poland & 0.183 & CGT & \\
\hline Portugal & 0.019 & CGT & Exempted Capital Gains until 2011. \\
\hline Romania & 0.148 & CGT & \\
\hline Russia & 0.187 & CGT \& PIT & $\begin{array}{l}\text { Tax only applies on gains from the sale of } \\
\text { companies with foreign Shareholders Capital } \\
\text { Gains treated as personal income after } 2003 \text {. }\end{array}$ \\
\hline Serbia & 0.165 & CGT & \\
\hline Singapore & 0.000 & CGT & \\
\hline South Africa & 0.108 & CGT & \\
\hline Spain & 0.205 & CGT & \\
\hline Sweden & 0.300 & CGT & \\
\hline Switzerland & 0.000 & CGT & $\begin{array}{l}\text { Gains from the sale of company shares are ex- } \\
\text { empted from taxationn }\end{array}$ \\
\hline Taiwan & 0.000 & CGT & $\begin{array}{l}\text { Gains from the sale of company shares are ex- } \\
\text { empted from taxation }\end{array}$ \\
\hline Thailand & 0.368 & PIT & \\
\hline Turkey & 0.000 & CGT & $\begin{array}{l}\text { Gains from the sale of company shares are ex- } \\
\text { empted from taxation }\end{array}$ \\
\hline United Kingdom & 0.312 & CGT & \\
\hline United States & 0.162 & CGT & \\
\hline Virgin Islands & 0.095 & CGT & \\
\hline
\end{tabular}




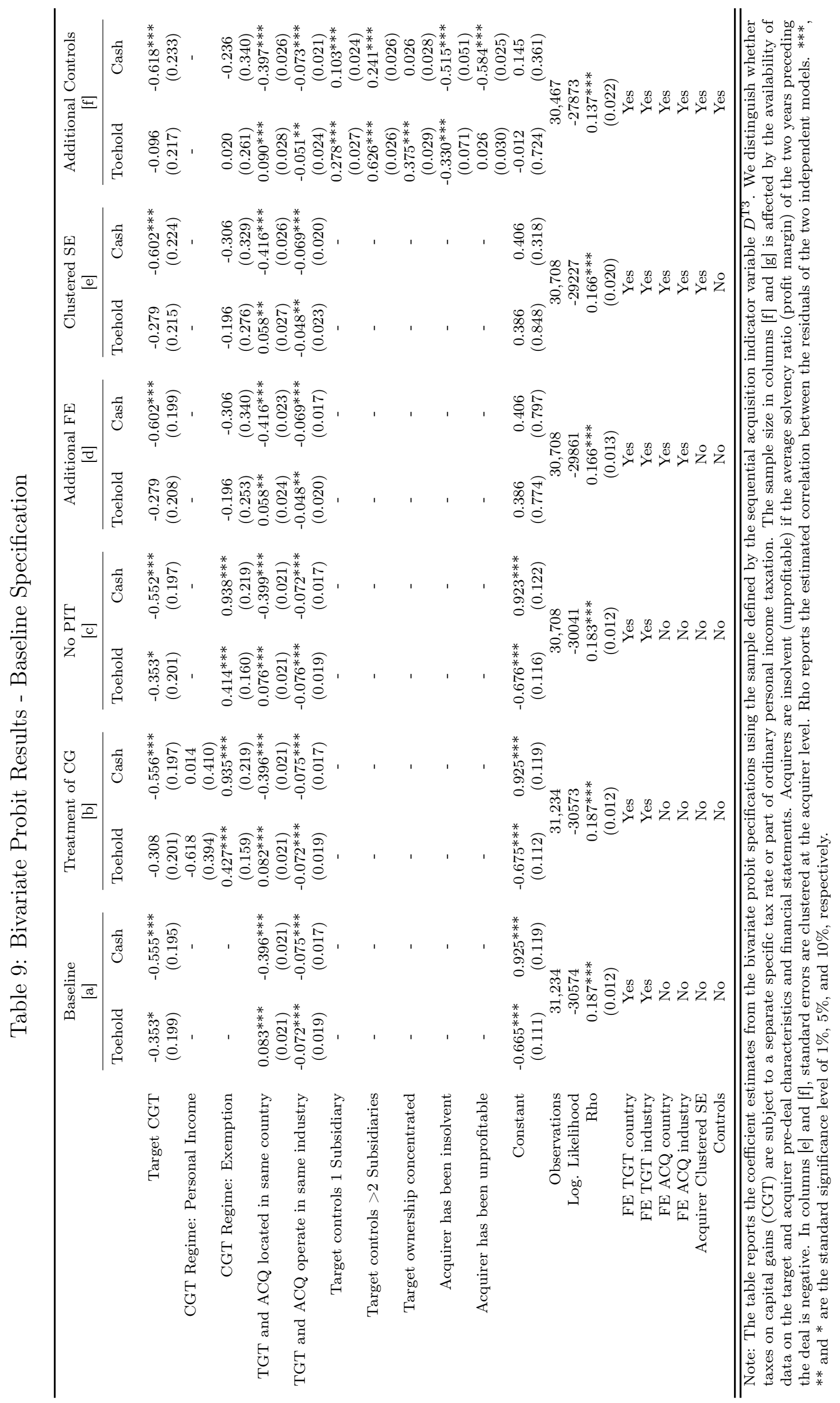




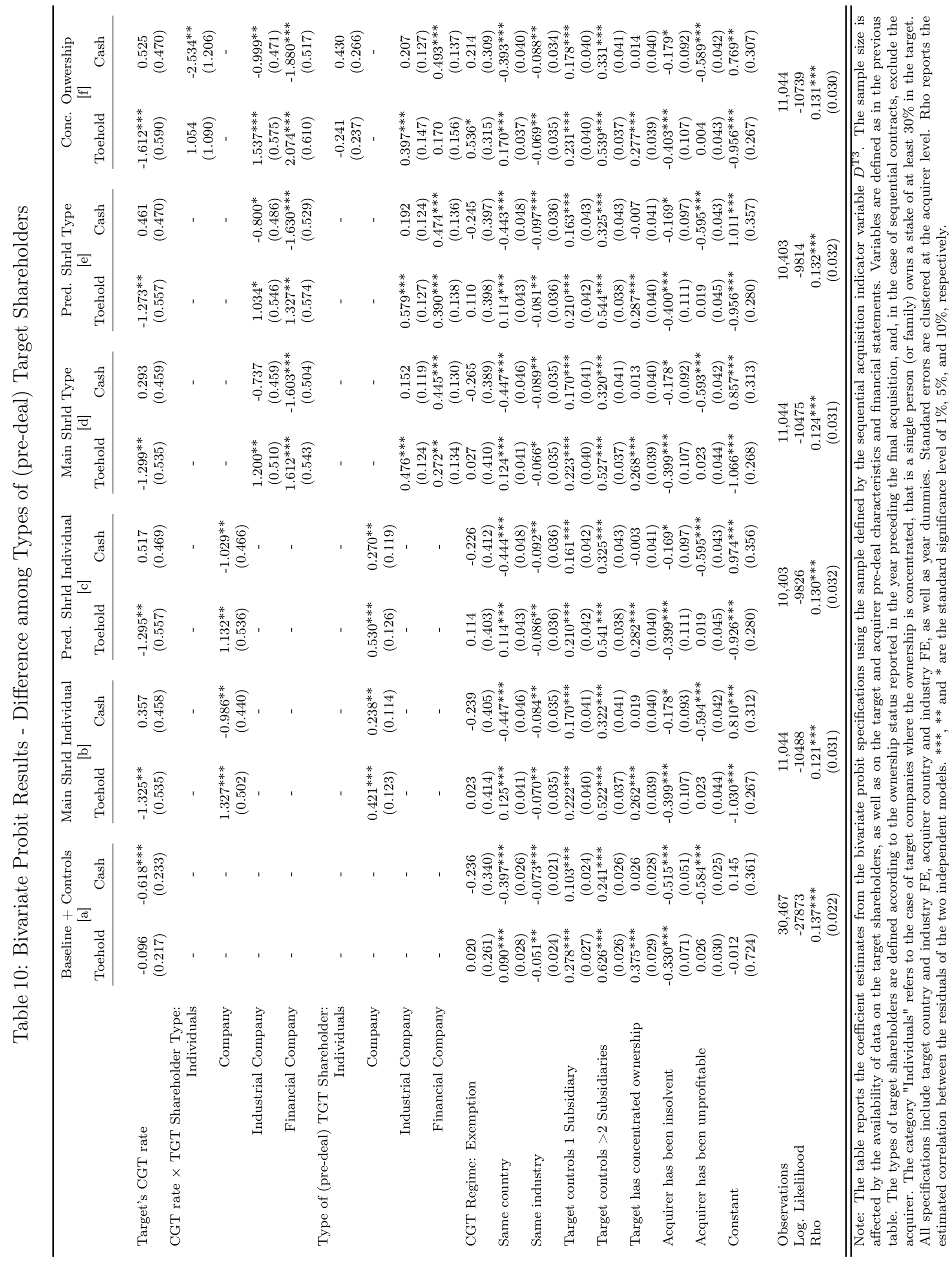


Table 11: Bivariate Probit Predictive Accuracy - Diagnostics

\begin{tabular}{|c|c|c|c|c|c|c|}
\hline & Seq. \& Cash & Seq. \& Equity & Full \& Cash & Full \& Equity & Sequential & Cash \\
\hline & \multicolumn{6}{|c|}{ Baseline Model, column [f] Table 9} \\
\hline Estimated Prob. & $\begin{array}{c}0.179 \\
(0.186)\end{array}$ & $\begin{array}{c}0.051 \\
(0.071)\end{array}$ & $\begin{array}{c}0.526 \\
(0.203)\end{array}$ & $\begin{array}{c}0.244 \\
(0.170)\end{array}$ & $\begin{array}{c}0.229 \\
(0.216)\end{array}$ & $\begin{array}{c}0.706 \\
(0.193)\end{array}$ \\
\hline Positive Predicted Values & 0.719 & 0.355 & 0.684 & 0.635 & 0.679 & 0.771 \\
\hline Negative Predicted Values & 0.864 & 0.952 & 0.697 & 0.790 & 0.840 & 0.644 \\
\hline \multirow[t]{2}{*}{ Correctly Classified } & 0.853 & 0.952 & 0.689 & 0.777 & 0.819 & 0.751 \\
\hline & \multicolumn{6}{|c|}{ Model with TGT Shareholder Types, column [f] Table 10} \\
\hline Estimated Prob. & $\begin{array}{c}0.282 \\
(0.221)\end{array}$ & $\begin{array}{c}0.081 \\
(0.100)\end{array}$ & $\begin{array}{c}0.455 \\
(0.224)\end{array}$ & $\begin{array}{c}0.182 \\
(0.145)\end{array}$ & $\begin{array}{c}0.364 \\
(0.248)\end{array}$ & $\begin{array}{c}0.737 \\
(0.199)\end{array}$ \\
\hline Positive Predicted Values & 0.709 & 0.409 & 0.698 & 0.608 & 0.679 & 0.803 \\
\hline Negative Predicted Values & 0.801 & 0.923 & 0.732 & 0.831 & 0.776 & 0.653 \\
\hline Correctly Classified & 0.786 & 0.921 & 0.717 & 0.823 & 0.746 & 0.781 \\
\hline
\end{tabular}

Table 12: Bivariate Probit - Marginal Effects of Capital Gain Taxes

\begin{tabular}{|c|c|c|c|c|c|}
\hline & $\begin{array}{l}\text { Overall Effect: } \\
\text { column [a] } \\
\text { table } 11\end{array}$ & $\begin{array}{l}\text { Individuals } \\
\text { with Dispersed } \\
\text { Ownership }\end{array}$ & $\begin{array}{c}\text { Individuals } \\
\text { with } \\
\text { Concentrated } \\
\text { Ownership }\end{array}$ & $\begin{array}{l}\text { Industrial } \\
\text { Companies }\end{array}$ & $\begin{array}{c}\text { Financial } \\
\text { Companies }\end{array}$ \\
\hline \multicolumn{6}{|l|}{ Marginal Probabilities: } \\
\hline $\operatorname{Pr}($ Sequential Contract $)$ & $\begin{array}{l}-0.022 \\
(0.049)\end{array}$ & $\begin{array}{c}-0.168^{* * *} \\
(0.060)\end{array}$ & $\begin{array}{l}-0.104 \\
(0.183)\end{array}$ & $\begin{array}{l}-0.024 \\
(0.093)\end{array}$ & $\begin{array}{c}0.147 \\
(0.118)\end{array}$ \\
\hline $\operatorname{Pr}($ Cash Finance $)$ & $\begin{array}{c}-0.179^{* * *} \\
(0.067)\end{array}$ & $\begin{array}{c}0.139 \\
(0.125)\end{array}$ & $\begin{array}{c}-0.595^{*} \\
(0.353)\end{array}$ & $\begin{array}{l}-0.124 \\
(0.090)\end{array}$ & $\begin{array}{c}-0.362^{* * *} \\
(0.114)\end{array}$ \\
\hline \multicolumn{6}{|l|}{ Joint Probabilities: } \\
\hline $\operatorname{Pr}($ Sequential Contract \& Cash Finance) & $\begin{array}{l}-0.050 \\
(0.039)\end{array}$ & $\begin{array}{c}-0.127^{* * *} \\
(0.047)\end{array}$ & $\begin{array}{l}-0.146 \\
(0.150)\end{array}$ & $\begin{array}{l}-0.064 \\
(0.076)\end{array}$ & $\begin{array}{l}-0.019 \\
(0.100)\end{array}$ \\
\hline $\operatorname{Pr}($ Full Contract \& Equity Finance) & $\begin{array}{c}0.150^{* * * *} \\
(0.056)\end{array}$ & $\begin{array}{l}-0.099 \\
(0.116)\end{array}$ & $\begin{array}{l}0.554^{*} \\
(0.328)\end{array}$ & $\begin{array}{c}0.084 \\
(0.061)\end{array}$ & $\begin{array}{c}0.196^{* *} \\
(0.083)\end{array}$ \\
\hline \multicolumn{6}{|l|}{ Conditional Probabilities: } \\
\hline $\operatorname{Pr}($ Cash Finance | Sequential Contract $)$ & $\begin{array}{c}-0.158^{* * *} \\
(0.061)\end{array}$ & $\begin{array}{c}0.153 \\
(0.104)\end{array}$ & $\begin{array}{c}-0.520^{*} \\
(0.312)\end{array}$ & $\begin{array}{l}-0.114 \\
(0.084)\end{array}$ & $\begin{array}{c}-0.346^{* * *} \\
(0.105)\end{array}$ \\
\hline $\operatorname{Pr}($ Cash Finance | Full Contract $)$ & $\begin{array}{c}-0.182^{* * *} \\
(0.069)\end{array}$ & $\begin{array}{c}0.151 \\
(0.126)\end{array}$ & $\begin{array}{l}-0.598^{*} \\
(0.355)\end{array}$ & $\begin{array}{l}-0.128 \\
(0.130)\end{array}$ & $\begin{array}{c}-0.387^{* * * *} \\
(0.119)\end{array}$ \\
\hline
\end{tabular}

Note: The table reports the average partial effects of a marginal change in the target country's capital gains tax rate on the marginal, joint and conditional probabilities of the contract structure and the method of finance. These partial effects are based on the estimates from the specification of column [f] in Table 10, a part from those reported in the first column, which refer to the baseline specification of column [f] in Table 9. The marginal effects reported in column 2 to 5 are computed on the basis of the subsample of contracts involving target firms whose main controlling shareholder is identified as being an individual (with or without dispersed ownership), an industrial company or a financial company. Standard errors are computed using the delta method. ${ }^{* * *},{ }^{* *}$ and ${ }^{*}$ are the standard significance level of $1 \%, 5 \%$, and $10 \%$, respectively. 


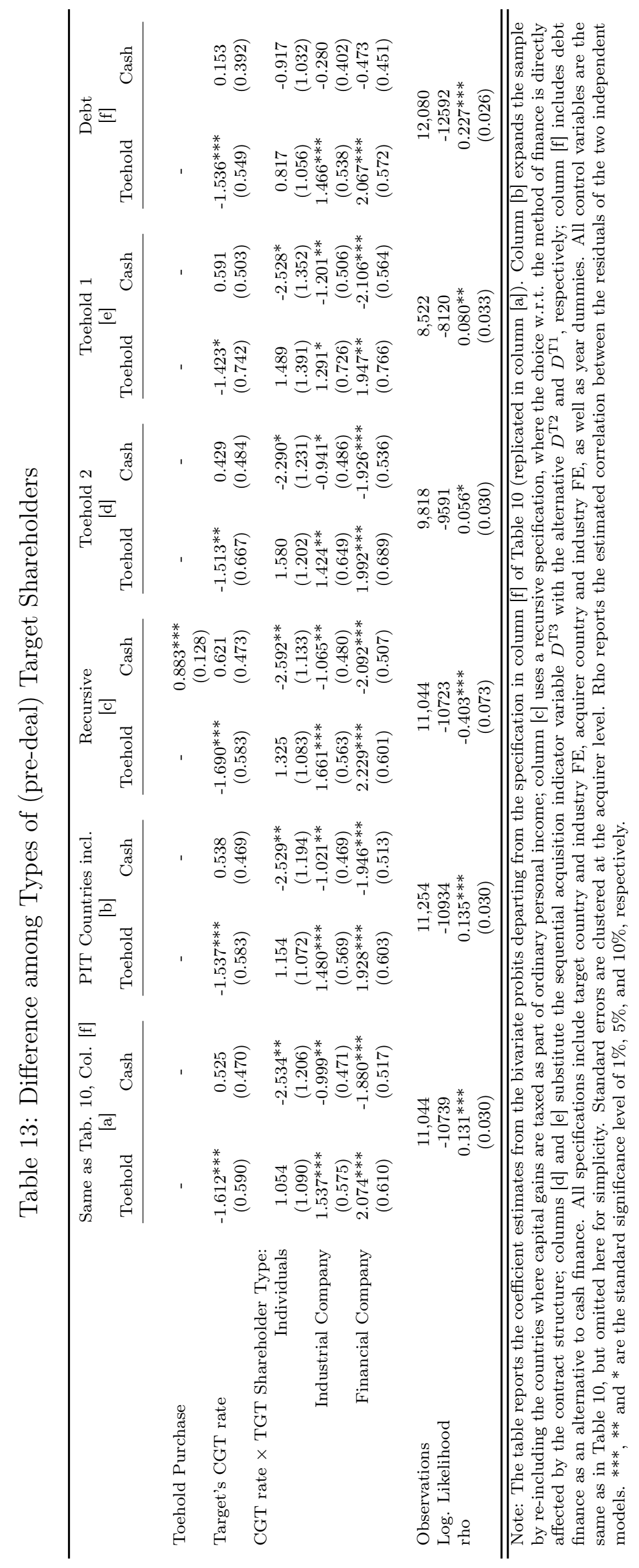

